\title{
Aryl-Substituted BIAN Complexes of Iron Dibromide: Synthesis, X-ray and Electronic Structure, and Catalytic Hydrosilylation Activity
}

Michael J. Supej, ${ }^{a}$ Alexander Volkov, ${ }^{a}$ Louisa Darko, ${ }^{a}$ Ryan A. West, ${ }^{b}$ Jonathan M. Darmon, ${ }^{c}$ Charles E. Schulz, ${ }^{b}$ Kraig A. Wheeler, ${ }^{\mathrm{d}}$ Helen M. Hoyt*a

a Department of Chemistry, Knox College, 2 E South St, Galesburg, IL, 61401, United States
${ }^{\mathrm{b}}$ Department of Physics, Knox College, 2 E South St, Galesburg, IL, 61401, United States
${ }^{\mathrm{c} C e n t e r}$ for Molecular Electrocatalysis, Physical Sciences Division, Pacific Northwest National
Laboratory, P.O. Box 999, K2-57, Richland, Washington 99352, United States
${ }^{\mathrm{d} D e p a r t m e n t ~ o f ~ C h e m i s t r y, ~ E a s t e r n ~ I l l i n o i s ~ U n i v e r s i t y, ~ C h a r l e s t o n, ~ I l l i n o i s ~ 61920, U n i t e d ~ S t a t e s . ~}$

*Corresponding author. Address: Department of Chemistry, Knox College, 2 E South St, Galesburg, IL, 61401, United States. Tel.: +1 3093417798.

E-mail address: hhoyt@knox.edu (H.M. Hoyt).

E-mail addresses: $\underline{\text { msupej@knox.edu }}$ (M.J. Supej); avolkov@knox.edu (A. Volkov); lodarko@knox.edu (L. Darko); rwest@knox.edu (R.A. West), jonathan.darmon@pnnl.gov (J.M. Darmon); $\quad \underline{\text { cschulz@knox.edu }} \quad$ (C.E. Schulz); $\quad \underline{\text { kawheeler@eiu.edu }} \quad$ (K.A. Wheeler); hhoyt@,knox.edu (H.M. Hoyt). 
Abstract: Anhydrous iron dibromide complexes bearing bidentate $\alpha$-diimine ligands ${ }^{A r} \mathrm{~N}=\mathrm{C}(\mathrm{Me})$ $(\mathrm{Me}) \mathrm{C}=\mathrm{N}^{A r}$ and ${ }^{A r} \mathrm{BIAN}(\mathrm{BIAN}=$ bis(imino)acenaphthene; $A r=\mathrm{dpp}$ and Mes; dpp = 2,6diisopropylphenyl; Mes = 2,4,6-trimethylphenyl) have been prepared and characterized by ${ }^{1} \mathrm{H}$ NMR spectroscopy. The aryl-substituted BIAN complexes were structurally characterized by single-crystal X-ray diffraction, and their metrical parameters are consistent with a redoxinnocent chelating ligand. A high-spin iron(II) electronic structure description for the ${ }^{A r}$ BIAN iron complexes is supported by Mössbauer spectroscopy, solution state magnetic measurements, and quantum-chemical calculations. Upon reduction, the iron complexes promote catalytic hydrosilylation of 1-hexene with phenylsilane at $22{ }^{\circ} \mathrm{C}$.

Keywords: Iron; $\alpha$-Diimine; Hydrosilylation; Catalysis; Bis(imino)acenaphthene

\section{Introduction}

Transition-metal catalyzed alkene hydrosilylation is used commercially for fine chemical synthesis and in the preparation of silicones for applications such as adhesives and sealing materials $[1,2]$. Given that many commercial organosilicon (Si-C) products are derived from the anti-Markovinikov addition of a tertiary silane $(\mathrm{Si}-\mathrm{H})$ to a terminal alkene $(\mathrm{C}=\mathrm{C})$, catalysts that demonstrate high terminal selectivity are an important industrial concern [2]. Historically, precious metal hydrosilylation catalysts such as Karstedt's $\left(\mathrm{Pt}_{2}\left\{\left[\left(\mathrm{CH}_{2}=\mathrm{CH}\right) \mathrm{SiMe}_{2}\right]_{2} \mathrm{O}\right\}_{3}\right)$ and Speier's $\left(\mathrm{H}_{2} \mathrm{PtCl}_{6} 6 \mathrm{H}_{2} \mathrm{O} /{ }^{i} \mathrm{PrOH}\right)$ catalysts have been used industrially [2]. Recently, iron has emerged as an attractive transition-metal catalyst for the hydrofunctionalization of terminal olefins given that iron is abundant with low cost, low toxicity, and potential for sustainable longterm commercial availability [3]. High selectivity and activity has been achieved by Chirik and 
co-workers in the hydrosilylation of terminal alkenes with reduced iron catalysts bearing redoxactive ligands, such as the tridentate pyridinediimine (PDI, I) iron bis(dinitrogen) pre-catalysts $\left({ }^{A r} \mathrm{PDI}\right) \mathrm{Fe}\left(\mathrm{N}_{2}\right)_{2}$ [4] and corresponding iron dialkyl pre-catalysts $\left({ }^{A r} \mathrm{PDI}\right) \mathrm{Fe}\left(\mathrm{CH}_{2} \mathrm{SiMe}_{3}\right)_{2}$ [5] (Figure 1). Additionally, Nakazawa and co-workers have reported that activation of substituted terpyridine (II) iron dibromide precatalysts selectively formed double hydrosilylation products with phenylsilane and 1-octene [6], Ritter and co-workers have disclosed that bis(iminopyridine) (III) iron precatalysts promoted the 1,4-addition of tertiary silanes to dienes to produce allylsilanes [7], and Huang and co-workers have demonstrated that phosphinite-iminopyridine (IV) iron complexes provided chemoselectivity in catalytic alkene hydrosilylation, tolerating several carbonyl-containing functional groups [8] (Figure 1).

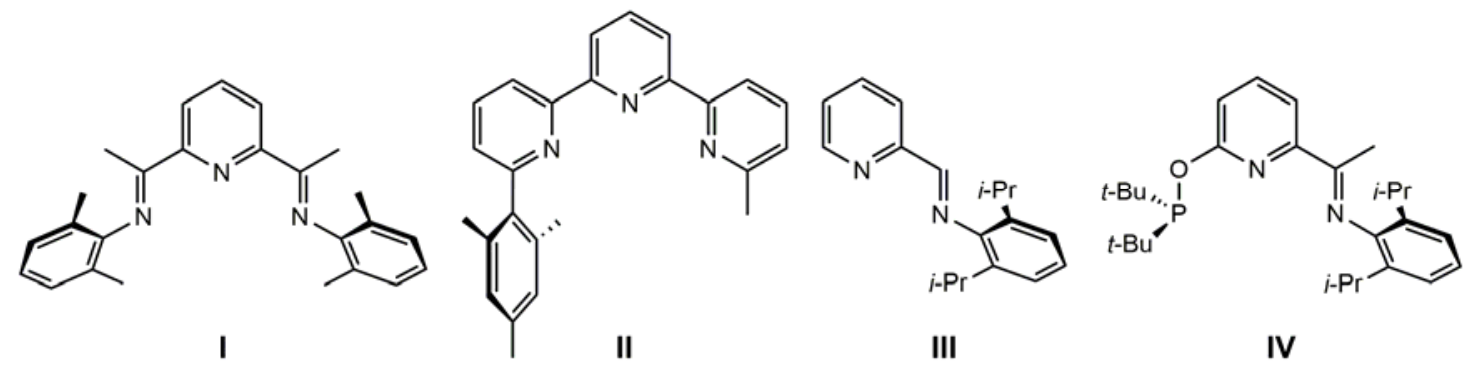

Figure 1. Representative ligands I-IV reported to support iron catalysts for the hydrosilylation of terminal olefins.

In contrast to the primarily tridentate ligands shown in Figure 1, bidentate $\alpha$-diimine ligands, such as the parent ${ }^{\mathrm{dpp}} \mathrm{N}=\mathrm{C}(\mathrm{Me})-(\mathrm{Me}) \mathrm{C}=\mathrm{N}^{\mathrm{dpp}}(\mathrm{dpp}=2,6$-diisopropylphenyl) ligand $[9,10]$ and the aryl bis(imino)acenapthene ( $\left.{ }^{A r} \mathrm{BIAN}\right)$ ligands (Figure 2$)$, have so far been less wellstudied to support the iron-catalyzed hydrosilylation of terminal olefins. Metal systems containing ${ }^{A r}$ BIAN ligands are efficient catalysts in processes such as alkyne hydrogenation, C-C coupling, and olefin polymerization [11]. Recently, Findlater and coworkers disclosed that a reduced, toluene-stabilized iron catalyst, ${ }^{\mathrm{dpp}} \mathbf{B I A N F e}\left(\eta^{6}-\mathrm{C}_{7} \mathbf{H}_{8}\right)$, successfully catalyzed the chemo- and regioselective hydrosilylation of aldehydes and ketones with $1 \mathrm{~mol} \%$ catalyst 
loadings in excellent yields at $70{ }^{\circ} \mathrm{C}$ [12]. In comparison to the parent $\alpha$-diimine ligand, the lower energy $\mathrm{C}=\mathrm{N} \pi^{*}$ orbitals for the conjugated ${ }^{A r} \mathrm{BIAN}$ ligands may be expected to act as better $\pi$-accepting ligands to the iron metal center, allowing the ${ }^{A r}$ BIAN ligands to better stabilize higher oxidation states of the coordinated iron center [11]. In a traditional sense, these proposed interactions can be considered as $\pi$-backbonding from the iron center, whereby electrons are donated from the metal's singly occupied orbital into an empty ligand $\pi^{*}$ orbital that is delocalized throughout the conjugated $\pi$-system of the ligand backbone (Figure 2), effectively stabilizing the complex and minimizing the formation of localized radical intermediates [13].

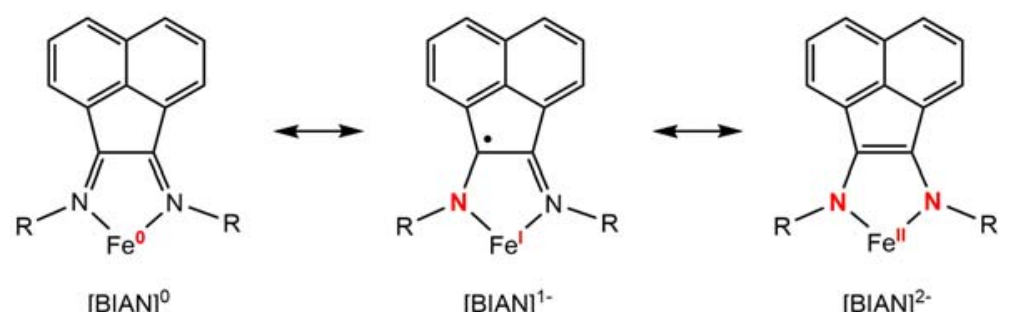

Figure 2. Delocalization of electrons in iron complexes supported by ${ }^{A r} \mathrm{BIAN}$ redox-active ligands $(\mathrm{R}=$ aryl $)$.

Building upon the previous work of Thomas and co-workers [14], we sought to develop an operationally simple iron-catalyzed hydrosilylation of 1-hexene in which low-valent iron catalysts were generated in-situ, with pre-catalysts prepared from relatively inexpensive commercially available materials in two linear steps. To this end, new anhydrous iron dibromide complexes bearing bidentate $\alpha$-diimine ${ }^{d p p} \mathrm{~N}=\mathrm{C}(\mathrm{Me})-(\mathrm{Me}) \mathrm{C}=\mathrm{N}^{\mathrm{dpp}},{ }^{\mathrm{Mes}} \mathrm{N}=\mathrm{C}(\mathrm{Me})-(\mathrm{Me}) \mathrm{C}=\mathrm{N}^{\mathrm{Mes}}$,

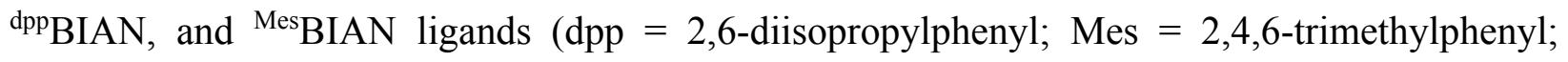
BIAN=bis(imino)acenaphthene) were prepared and characterized by ${ }^{1} \mathrm{H}$ NMR spectroscopy. The structures of the ${ }^{A r}$ BIAN iron complexes were investigated by single crystal X-ray diffraction, and the electronic structure of these pre-catalysts was elucidated by solution state magnetic measurements, Mössbauer spectroscopy, and by DFT computational analysis. Subsequent in-situ 
reduction of the iron complexes promoted the hydrosilylation of 1-hexene under mild and solvent free conditions.

\section{Results and discussion}

\subsection{Synthesis and spectroscopic characterization of iron complexes}

The ${ }^{A r}$ BIAN iron dibromide pre-catalysts were prepared in two linear steps from commercially available starting materials and were characterized by IR and ${ }^{1} \mathrm{H}$ NMR spectroscopy. First, the substituted ${ }^{A r}$ BIAN ligands were prepared by acid-catalyzed condensation of acenaphthenequinone (1) with two equivalents of the appropriate aniline (2a/2b) following a similar protocol to that reported by Yuan et. al [15] (Figure 3). The ${ }^{A r} \mathrm{BIANFeBr}_{2}$ pre-catalysts were then synthesized by addition of anhydrous iron(II) bromide to a solution of the ${ }^{A r}$ BIAN ligand in THF (3a) or $\mathrm{CH}_{2} \mathrm{Cl}_{2}$ (3b) following a similar procedure described by Findlater and coworkers for the analogous ${ }^{d p p} \mathrm{BIANFeCl}_{2}$ complex [12]. While ${ }^{\mathrm{dpp}} \mathrm{BIANFeBr}_{2}$ (4a) was isolated from THF in high yield (95\%), ${ }^{\mathrm{Mes} B I A N F e B r} 2$ (4b) could not be cleanly isolated when prepared in this coordinating solvent, as THF was found to bind to the iron center and provided an intractable mixture of $\mathbf{4 b} / \mathbf{4 b} \cdot \mathbf{T H F}$ based on broadened and shifted THF resonances at 5.93 and 4.09 ppm observed by ${ }^{1} \mathrm{H}$ NMR spectroscopy (Appendix A, Figure A.4.1). Performing the reaction in non-coordinating $\mathrm{CH}_{2} \mathrm{Cl}_{2}$ solvent allowed for isolation of purified $\mathbf{4 b}$ without a coordinated Lewis base in reasonable yield (75\%). The solid state IR C=N stretching frequencies of $4 \mathbf{a}\left(1643,1614 \mathrm{~cm}^{-1}\right)$ and $4 \mathbf{b}\left(1653,1622 \mathrm{~cm}^{-1}\right)$ have lower $\mathrm{C}=\mathrm{N}$ stretching frequencies than the corresponding ${ }^{A r}$ BIAN ligands $\left(3 \mathbf{a}: 1668 \mathrm{~cm}^{-1} ; \mathbf{3 b}: 1674 \mathrm{~cm}^{-1}\right)$ and slightly higher frequencies than are typical of $\alpha$-diimine supported iron(II) dichloride species $[\mathrm{RN}=\mathrm{C}(\mathrm{Ph})-\mathrm{C}(\mathrm{Ph})=\mathrm{NR}] \mathrm{FeCl}_{2}$ 
$(\mathrm{R}=t-\mathrm{Bu}, \mathrm{Cy})$ with non-conjugated backbones that display $\mathrm{C}=\mathrm{N}$ stretches between 1600 and $1611 \mathrm{~cm}^{-1}[16]$.

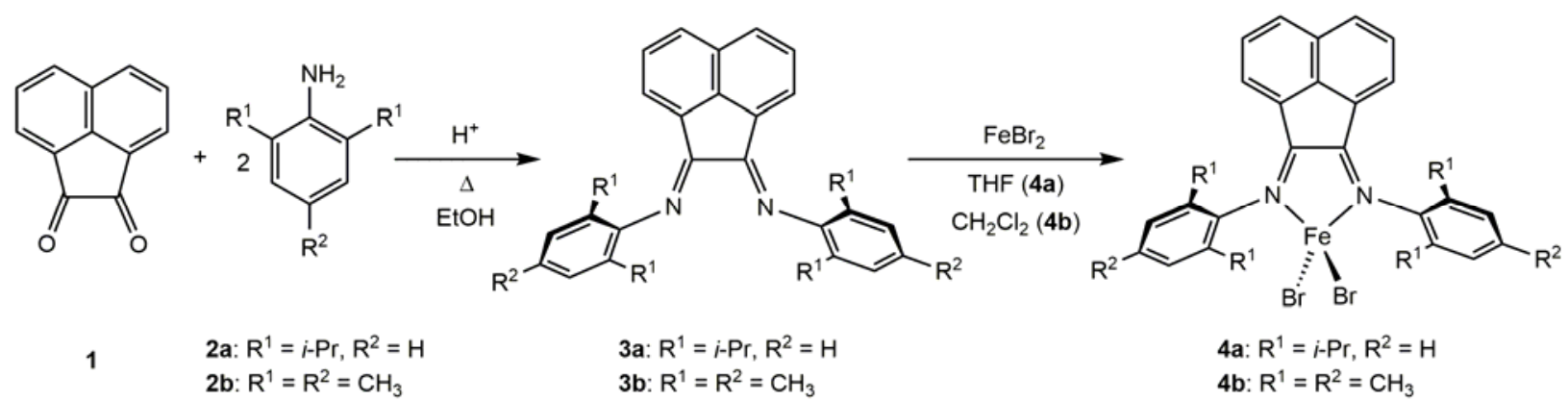

Figure 3. Synthesis of ${ }^{A r} \mathrm{BIANFeBr} 2$ complexes $\mathbf{4 a} / \mathbf{4 b}$ from commercially available starting materials $\mathbf{1}$ and $\mathbf{2 a} / \mathbf{2 b}$.

Similarly, the parent $\alpha$-diimine iron dibromide complexes $\left[{ }^{\mathrm{dpp}} \mathrm{N}=\mathrm{C}(\mathrm{Me})\right.$ $\left.(\mathrm{Me}) \mathrm{C}=\mathrm{N}^{\mathrm{dpp}}\right] \mathrm{FeBr}_{2}(\mathbf{5 a})$ and $\left[{ }^{\mathrm{Mes}} \mathrm{N}=\mathrm{C}(\mathrm{Me})-(\mathrm{Me}) \mathrm{C}=\mathrm{N}^{\mathrm{Mes}}\right] \mathrm{FeBr}_{2}$ (5b) (Figure 10, vide infra) have been prepared in two linear steps from commercially available materials following an analogous procedure to that reported by Chirik and coworkers for the preparation of $\left[{ }^{\mathrm{dpp}} \mathrm{N}=\mathrm{C}(\mathrm{Me})\right.$ $(\mathrm{Me}) \mathrm{C}=\mathrm{N}^{\mathrm{dpp}}$ ] $\mathrm{FeCl}_{2}$ [9]. Upon addition of two equivalents of the appropriate aniline $(\mathbf{2} \mathbf{a} / \mathbf{2} \mathbf{b})$ to 2,3-butanedione, each $\alpha$-diimine ligand was isolated following an analogous procedure to that reported by Yuan et. al [17], followed by subsequent addition of $\mathrm{FeBr}_{2}$ to the ligand in a solution of either THF (5a) or $\mathrm{CH}_{2} \mathrm{Cl}_{2}$ (5b) to form the desired parent $\alpha$-diimine iron dibromide complexes in excellent yields of $90 \%(\mathbf{5 a})$ and $95 \%(\mathbf{5 b})$. The structures of complexes $\mathbf{5 a}$ and $\mathbf{5 b}$ were primarily characterized structurally by ${ }^{1} \mathrm{H}$ NMR spectroscopy, and their spectra demonstrated analogous features to those of $\mathbf{4 a}$ and $\mathbf{4 b}$, respectively, as described below.

The contact-shifted resonances in the ${ }^{1} \mathrm{H}$ NMR spectra for the paramagnetic iron complexes are broadened and the chemical shifts are significantly more diffuse than those of the corresponding diamagnetic ligands. Paramagnetic spectra are assigned primarily based on 
integrated signal intensities and chemical shifts (Figure 4). For complex 4a, the diastereotopic, magnetically inequivalent isopropyl methyl groups (due to hindered rotation around the $\mathrm{N}$-Caryl bonds) were found to integrate to $12 \mathrm{H}$ each at -4.02 and $2.77 \mathrm{ppm}$, and the $p-A r(2 \mathrm{H})$ and $m-A r$ (4H) signals were observed at -18.53 and $5.64 \mathrm{ppm}$, respectively (Figure 4a). With the same $\mathrm{N}$ aryl diisopropylphenyl substituent, complex 5a demonstrates similar features in its ${ }^{1} \mathrm{H}$ NMR spectrum to complex 4a, such as resonances for the diasterotopic isopropyl methyl groups at 3.70 and $-5.75 \mathrm{ppm}$, and the $p-A r$ and $m-A r$ signals were observed at -16.65 and $7.38 \mathrm{ppm}$, respectively (Figure 4c). The isopropyl $\mathrm{CH}$ resonances for both $\mathbf{4 a}$ and $\mathbf{5 a}$ were not located under these NMR experiment parameters as is typical for iron complexes with orthogonal ligands bearing ortho $i$-Pr substituents [9]; these resonances are likely to be significantly broadened due to their close proximity to the iron center. In the ${ }^{1} \mathrm{H}$ NMR spectrum of complex $\mathbf{4} \mathbf{b}$, the $o$ - and $p$ Me peaks of the $N$-mesityl substituent were located at $11.18 \mathrm{ppm}(12 \mathrm{H})$ and $16.18 \mathrm{ppm}(6 \mathrm{H})$, respectively (Figure $4 \mathrm{~b}$ ), and the $m-A \mathrm{r}(4 \mathrm{H})$ signal was observed at $5.93 \mathrm{ppm}$. With the same $N$ mesityl substituent, complex 5b demonstrates similar features in its ${ }^{1} \mathrm{H}$ NMR spectrum to complex $\mathbf{4 b}$, such as the resonances for the $o$ - and $p$-Me peaks located at 7.53 and $15.36 \mathrm{ppm}$, respectively, and the $m-A \mathrm{r}$ signal was observed at $2.55 \mathrm{ppm}$ (Figure $4 \mathrm{~d}$ ). For both $\mathbf{5 a}$ and $\mathbf{5 b}$, the backbone imine methyl groups are located the farthest from their diamagnetic reference values, with $\mathrm{C}_{\mathrm{im}}-\mathrm{Me}$ peaks at $74.37 \mathrm{ppm}$ (5a) and $118.20 \mathrm{ppm}$ (5b). For both $4 \mathbf{a}$ and $4 \mathbf{b}$, the acenaphthene backbone aryl resonances are shifted both upfield and downfield slightly from their corresponding diamagnetic reference values. For all four iron complexes, the peaks attributed to the ortho substituents are the most paramagnetically broadened, with peak-width at half-height (400 MHz spectrometer) measurements greater than $100 \mathrm{~Hz}$, compared to other peaks 
with these values typically below $50 \mathrm{~Hz}$; this is presumably due to the locations of these hydrogen atoms with respect to the iron metal center (vide infra).
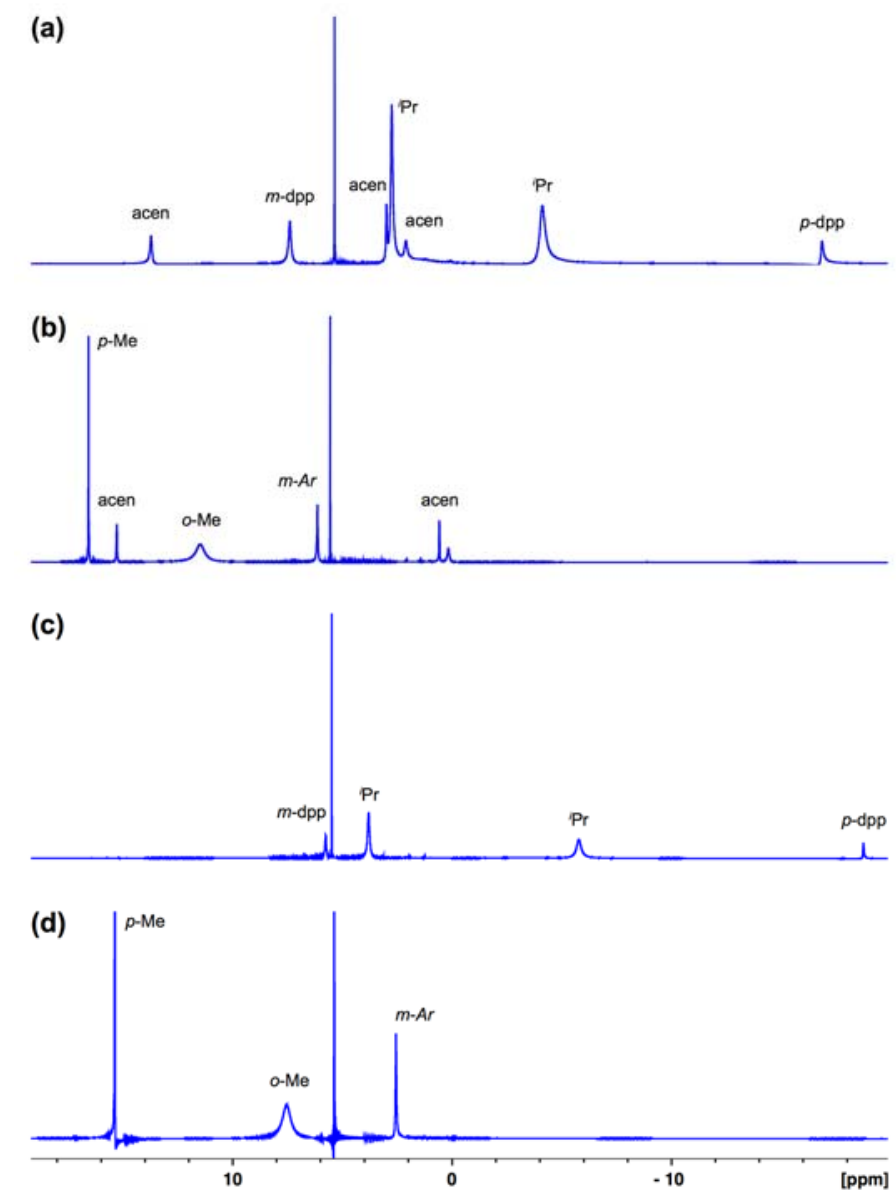

Figure 4. Comparison of ${ }^{1} \mathrm{H} N \mathrm{NR}$ spectra $\left(400 \mathrm{MHz}, \mathrm{CD}_{2} \mathrm{Cl}_{2}\right.$ ) for (a) $\mathbf{4 a}$; (b) $\mathbf{4 b}$; (c) $\mathbf{5 a}$; (d) $\mathbf{5 b}$; $\left(\mathrm{C}_{\mathrm{im}}-\mathrm{Me}\right.$ peaks at $74.37 \mathrm{ppm}(\mathbf{5 a})$ and $118.20 \mathrm{ppm}(\mathbf{5 b})$ not shown; $\mathrm{CHMe} 2$ peaks for $\mathbf{4 a}$ and $\mathbf{5 a}$ not located).

\section{$2.2 \mathrm{X}$-ray structures of iron complexes $\mathbf{4 a}$ and $\mathbf{4 b}$}

Single crystals of $\mathbf{4 a}$ and $\mathbf{4 b}$ suitable for X-ray diffraction analysis were obtained from dichloromethane at $-32{ }^{\circ} \mathrm{C}$. Table 1 includes pertinent data collection and refinement parameters for $4 \mathbf{a}$ and $\mathbf{4 b}$, while selected bond distances and angles are provided in Table 2. Figure 5 provides molecular views and selected dihedral angles for $\mathbf{4 a}(l e f t)$ and $\mathbf{4 b}($ right $)$, illustrating the distorted pseudo-tetrahedral geometry of both complexes with $\tau_{4}$ values $(0.90$ for $\mathbf{4 a}$ and 0.91 for 
4b) consistent with an idealized tetrahedral $\left(\tau_{4}=1.00\right)$ rather than an idealized square planar $\left(\tau_{4}\right.$ $=0.00)$ shape [18]. Both complexes exhibit smaller N-Fe-N' angles than expected for a complex with tetrahedral geometry $\left(78.7(2)^{\circ}(\mathbf{4 a}) ; 78.87(19)^{\circ}(\mathbf{4 b}) ; 78.61(14)^{\circ}\left({ }^{\mathrm{dpp}} \mathrm{BIANFeCl}_{2}\right)[11]\right)$, while correspondingly larger Br-Fe-Br' angles $\left(117.03(6)^{\circ}(\mathbf{4 a}) ; 115.39(5)^{\circ}(\mathbf{4 b})\right)$ are observed. In part, these relatively smaller angles may be due to the constraints imposed by the tied-back, planar BIAN ligand backbone, as a relatively larger N-Fe-N' angle is provided to the 5membered chelate for a less constrained $\alpha$-diimine ligand backbone such as that observed for the $[\mathrm{CyN}=\mathrm{C}(\mathrm{Ph})-\mathrm{C}(\mathrm{Ph})=\mathrm{NCy}] \mathrm{FeCl}_{2}$ complex $\left(\mathrm{N}-\mathrm{Fe}-\mathrm{N}^{\prime}: 119.24(9)^{\circ}\right)$ [15]. In both complexes $4 \mathbf{a}$ and 4b, the aryl substituents are oriented orthogonally to the plane in which the ligand backbone is situated, as shown by the $\mathrm{C}-\mathrm{C}_{A r} \mathrm{~N}-\mathrm{C}_{\mathrm{im}}$ dihedral angles near to $90^{\circ}$ for both complexes (Figure 5).

Table 1. Selected crystallographic and refinement data for $\mathbf{4 a}$ and $\mathbf{4 b}$.

\begin{tabular}{|c|c|c|}
\hline & $4 a$ & $4 b$ \\
\hline Empirical Formula & $\mathrm{C}_{36} \mathrm{H}_{40} \mathrm{Br}_{2} \mathrm{FeN}_{2}$ & $\mathrm{C}_{30} \mathrm{H}_{28} \mathrm{Br}_{2} \mathrm{FeN}_{2}$ \\
\hline Formula Weight & 716.38 & 632.21 \\
\hline Crystal color, Habit & green, plate & red, plate \\
\hline Crystal dimensions (mm) & $0.18 \times 0.14 \times 0.08$ & $0.38 \times 0.12 \times 0.10$ \\
\hline Crystal system & monoclinic & orthorhombic \\
\hline Space group & $P 2_{1 / c}$ & Pccn \\
\hline$Z$ & 8 & 8 \\
\hline$a(\AA)$ & $27.1504(13)$ & $22.6321(7)$ \\
\hline$b(\AA)$ & $12.0306(6)$ & $16.7681(5)$ \\
\hline$c(\AA)$ & $22.8626(9)$ & $17.2755(6)$ \\
\hline$\beta\left({ }^{\circ}\right)$ & $113.511(3)$ & 90 \\
\hline$V\left(\AA^{3}\right)$ & $6847.8(6)$ & $6556.0(4)$ \\
\hline$D_{\text {calc }}\left(\mathrm{g} \mathrm{cm}^{-3}\right)$ & 1.390 & 1.281 \\
\hline$\mu(\mathrm{CuK} \alpha)\left(\mathrm{cm}^{-1}\right)$ & 6.450 & 6.670 \\
\hline$T(\mathrm{~K})$ & $100(2)$ & $100(2)$ \\
\hline$\lambda(\AA)$ & 1.54178 & 1.54178 \\
\hline $\begin{array}{l}\text { Reflections with } \\
I>2.0 \sigma(I)\end{array}$ & 14377 & 5607 \\
\hline Residuals: ${ }^{a} R ; R_{\mathrm{w}} ; R_{\mathrm{all}}$ & $0.0619 ; 0.1394 ; 0.0845$ & $0.0738 ; 0.1631 ; 0.0779$ \\
\hline Goodness of Fit Indicator & 1.062 & 1.231 \\
\hline
\end{tabular}


Table 2. Selected distances $(\AA)$ and angles $\left({ }^{\circ}\right)$ for $\mathbf{4 a}$ and $\mathbf{4 b}$ with computed values included in square brackets (vide infra).

\begin{tabular}{|c|c|c|}
\hline & $4 \mathbf{a}$ & $4 b$ \\
\hline $\mathrm{Fe}-\mathrm{Br}$ & $2.3434(14)[2.399]$ & $2.3649(12)[2.400]$ \\
\hline Fe-Br' & $2.3708(15)[2.401]$ & $2.3582(12)[2.401]$ \\
\hline $\mathrm{Fe}-\mathrm{N}$ & $2.140(6)[2.221]$ & $2.137(5)[2.230]$ \\
\hline $\mathrm{Fe}-\mathrm{N}$ & $2.142(6)[2.226]$ & $2.142(5)[2.238]$ \\
\hline $\mathrm{N}-\mathrm{C}_{\text {im }}$ & $1.277(9)$ [1.279] & $1.273(8)[1.279]$ \\
\hline$N^{\prime}-C_{i m}{ }^{\prime}$ & $1.287(9)[1.278]$ & $1.275(8)[1.280]$ \\
\hline $\mathrm{C}_{\mathrm{im}}-\mathrm{C}_{\mathrm{im}}$ & $1.508(10)[1.521]$ & $1.518(9)[1.523]$ \\
\hline N-Fe-N' & $78.7(2)[76.72]$ & 78.87(19) [76.77] \\
\hline $\mathrm{Br}-\mathrm{Fe}-\mathrm{Br}$ & $117.03(6)[126.85]$ & $115.39(5)[123.55]$ \\
\hline $\mathrm{N}-\mathrm{Fe}-\mathrm{Br}$ & $113.30(17)[103.65]$ & $113.74(14)[113.67]$ \\
\hline $\mathrm{N}-\mathrm{Fe}-\mathrm{Br}{ }^{\prime}$ & $113.69(19)[117.28]$ & $113.96(14)[108.73]$ \\
\hline $\mathrm{N}^{\prime}-\mathrm{Fe}-\mathrm{Br}$ & $115.79(18)$ [113.90] & $116.78(14)[112.46]$ \\
\hline $\mathrm{N}^{\prime}-\mathrm{Fe}-\mathrm{Br}{ }^{\prime}$ & $112.47(18)[107.60]$ & $112.99(14)[112.14]$ \\
\hline
\end{tabular}
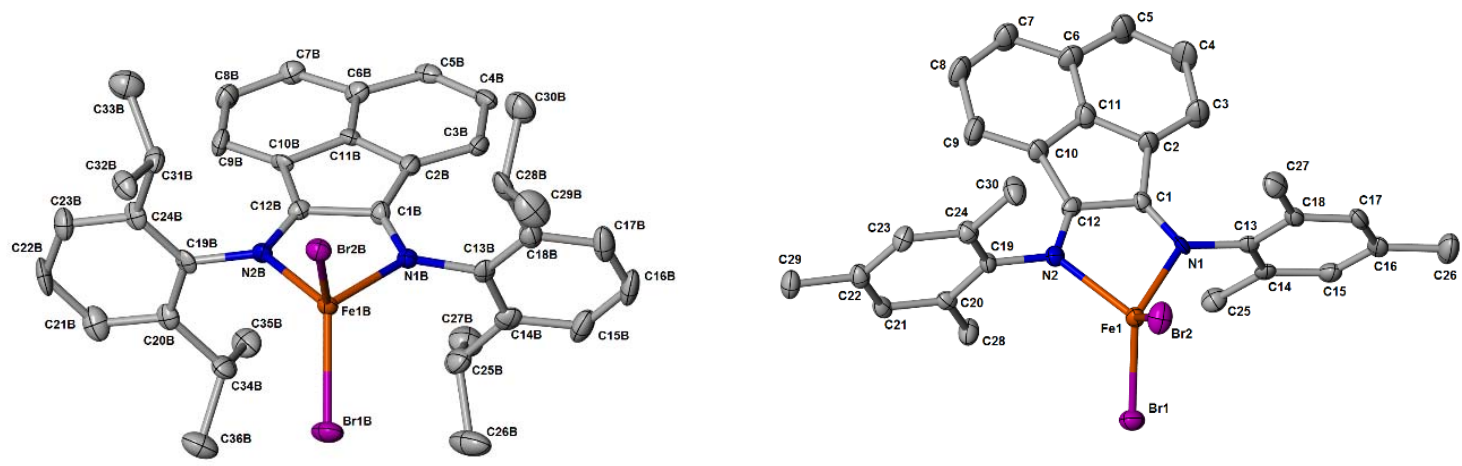

Figure 5. Molecular views illustrating the geometry and atom labeling scheme with the hydrogen atoms omitted for clarity for $4 \mathbf{a}($ left $)$; selected dihedral angles $\left(^{\circ}\right)$ listed as absolute values: C(14B)-C(13B)-N(1B)-C(1B): 80.5(9), C(18B)-C(13B)-N(1B)-C(1B): 96.8(9), C(20B)$\mathrm{C}(19 \mathrm{~B})-\mathrm{N}(2 \mathrm{~B})-\mathrm{C}(12 \mathrm{~B})$ : 91.2(9), C(24B)-C(19B)-N(2B)-C(12B): 87.8(9); and $\mathbf{4 b}$ (right); $\mathbf{4 b}$ (right); selected dihedral angles $\left({ }^{\circ}\right)$ listed as absolute values: $\mathrm{C}(14)-\mathrm{C}(13)-\mathrm{N}(1)-\mathrm{C}(1)$ : 82.7(7), $\mathrm{C}(18)-\mathrm{C}(13)-\mathrm{N}(1)-\mathrm{C}(1)$ : 97.9(7)， C(20)-C(19)-N(2)-C(12): 95.4(7)， C(24)-C(19)-N(2)-C(12): $85.8(7)$.

The bond lengths of $\mathbf{4 a}$ and $\mathbf{4 b}$ are similar to other reported $\alpha$-diimine iron dihalide complexes, such as $[\mathrm{CyN}=\mathrm{C}(\mathrm{Ph})-\mathrm{C}(\mathrm{Ph})=\mathrm{NCy}] \mathrm{FeCl}_{2}$ [16]. In general, the $\mathrm{Fe}-\mathrm{N}$ bond lengths are longer in complexes 4a (2.140(6) $\AA ; 2.142(6) \AA), 4 \mathbf{b}(2.137(5) \AA ; 2.142(5) \AA)$, and 
${ }^{\mathrm{dpp}} \mathrm{BIANFeCl}_{2}(2.132(4) \AA ; 2.140(4) \AA)[12]$ than in the $[\mathrm{CyN}=\mathrm{C}(\mathrm{Ph})-\mathrm{C}(\mathrm{Ph})=\mathrm{NCy}] \mathrm{FeCl}_{2}$ complex $(2.077(3) \AA ; 2.077(3) \AA)[16]$. This may result from decreased $\sigma$-donation of the ${ }^{A r}$ BIAN ligands due to lower overlap with the iron orbitals given the relatively smaller N-Fe-N' angles required by the tied-back BIAN ligand backbone as compared to the a less constrained $\alpha$ diimine ligand backbone in $[\mathrm{CyN}=\mathrm{C}(\mathrm{Ph})-\mathrm{C}(\mathrm{Ph})=\mathrm{NCy}] \mathrm{FeCl}_{2}$. The position of the aryl substituents orthogonal to the N-Fe-N' plane may play a role in the observed differences in catalytic reactivity of $\mathbf{4 a}$ and $\mathbf{4 b}$ (vide infra). The ${ }^{\mathrm{Mes}} \mathrm{BIAN}$ ligand for $\mathbf{4 b}$ allows for a more open

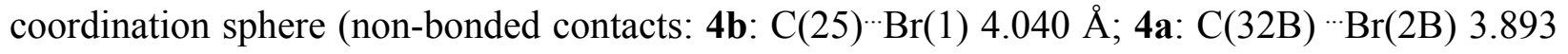
$\AA$ ) about the metal center due to the smaller methyl groups as compared to the larger isopropyl groups on the dppBIAN ligand. Due to steric effects, the Mes BIAN ligand may allow additional ligands to bind to the metal center, such as THF, which was observed to occur on preparation of the proposed ${ }^{\text {Mes }}$ BIANFeBr2 THF (4b-THF) complex in THF solvent (vide supra).

While ${ }^{A r}$ BIAN ligands have been reported to accept electrons when treated with reducing agents such as $\mathrm{Na}$, or when bound to metal centers of varied oxidation states $[19,20]$, the bond lengths for the ${ }^{A r}$ BIAN ligands in complexes $\mathbf{4 a}$ and $\mathbf{4 b}$ are consistent with the redox-innocent [13] form of the ligand. When compared to other metal systems supported by ${ }^{A r}$ BIAN ligands, the $\mathrm{C}_{\mathrm{im}}=\mathrm{N}$ and $\mathrm{C}_{\mathrm{im}-\mathrm{C}} \mathrm{C}_{\mathrm{im}}$ bond lengths found in $4 \mathrm{a}(\mathrm{C}=\mathrm{N}: 1.277(9) \AA ; 1.287(9) \AA ;$ C-C: $1.508(10)$ $\AA ̊), 4 \mathbf{b}(\mathrm{C}=\mathrm{N}: 1.273(8) \AA ̊ ; 1.275(8) \AA \AA ; \mathrm{C}-\mathrm{C}: 1.518(9) \AA)$, and ${ }^{\mathrm{dpp}} \mathrm{BIANFeCl}_{2}(\mathrm{C}=\mathrm{N}: 1.283(7) \AA$ C-C: $1.506(6) \AA$ ) [12] show similarities to $\left[{ }^{\mathrm{dpp}} \mathrm{BIAN}\right]^{0} \mathrm{Pd}^{0}$ complexes (such as $\mathbf{V}$ in Figure 6) bearing a non-reduced, redox-innocent $\left[{ }^{\mathrm{dpp}} \mathrm{BIAN}\right]^{0}$ ligand $(\mathrm{C}=\mathrm{N}: 1.276 \AA$; $1.297 \AA$; C-C: 1.506 $\AA$ ) [18]. However, in $\left[{ }^{A r} \mathrm{BIAN}\right]^{2-} \mathrm{Mg}^{\mathrm{II}}$ complexes such as VII, the bond lengths (C-N: $1.401 \AA$; $1.408 \AA ; \mathrm{C}=\mathrm{C}: 1.389 \AA$ ) [19] indicate that the ligand can be described as an ene-diamide structure with expanded C-N and contracted C-C bonds. Crystallographic data for $\left[{ }^{A r} \mathrm{BIAN}\right]^{1-}$ 
bound to ferrous iodide $\left(\mathrm{C}^{\cdots} \mathrm{N}: 1.328 \AA ; 1.330 \AA ; \mathrm{C} \cdots \mathrm{C}: 1.437 \AA\right)$ in the $\left[\left({ }^{\mathrm{dpp}} \mathrm{BIAN}\right){ }^{1-} \mathrm{Fe}^{\mathrm{II}}(\mu-\mathrm{I})\right]_{2}$ dimer VI [20] has shown that the ${ }^{A r} \mathrm{BIAN}^{1-}$ can stabilize a ligand radical anion through resonance as the $\mathrm{C} \cdots \mathrm{N}$ and $\mathrm{C} \cdots \mathrm{C}$ bond lengths are intermediate between the redox-innocent $\alpha$-diimine $\left[{ }^{A r} \mathrm{BIAN}\right]^{0}$ and ene-diamide $\left[{ }^{A r} \mathrm{BIAN}\right]^{2-}$ forms of the ligand. The agreement of the $\mathrm{C}_{\mathrm{im}}=\mathrm{N}$ and $\mathrm{C}_{\mathrm{im}}{ }^{-}$ $\mathrm{C}_{\mathrm{im}}$ bond lengths for $\mathbf{4 a}$ and $\mathbf{4 b}$ with the non-chelated ${ }^{\mathrm{dpp}} \mathrm{BIAN}(\mathrm{C}=\mathrm{N}: 1.28 \AA$; C-C: $1.53 \AA$ ) [21] and ${ }^{\text {Mes }}$ BIAN (C=N: $1.27 \AA$; C-C: $\left.1.528 \AA\right)$ [22] ligands, respectively, further indicates that these complexes $\mathbf{4 a}$ and $\mathbf{4 b}$ contain redox-innocent ${ }^{A r}$ BIAN ligands.
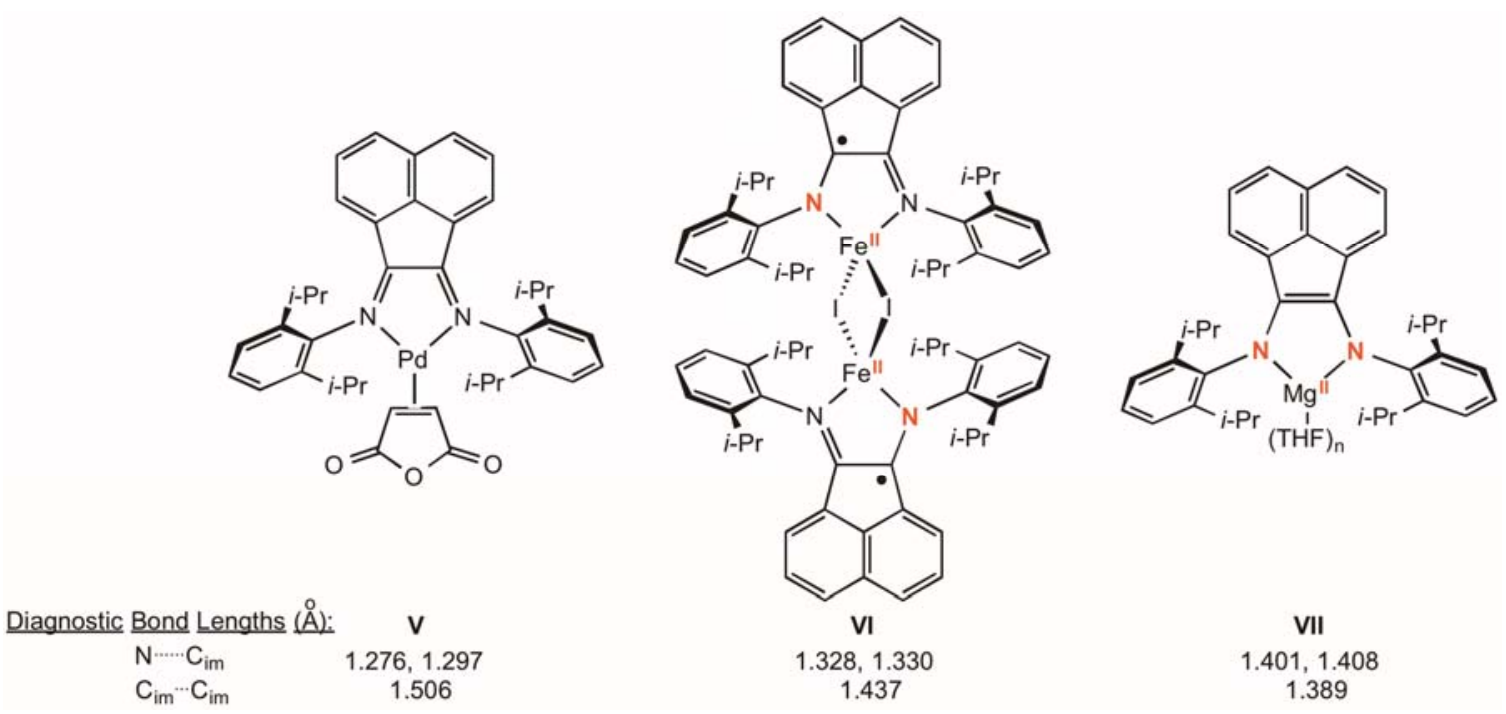

Figure 6. Metal systems V-VII supported by ${ }^{A r}$ BIAN ligands of different oxidation states $[19,20]$.

\subsection{Electronic structure of bis(imino)acenaphthene iron complexes}

The electronic structures of the ${ }^{A r}$ BIAN iron dibromide complexes $4 \mathbf{a}$ and $\mathbf{4 b}$ were investigated using a combination of metrical parameters from X-ray diffraction (vide supra), solid state Mössbauer spectroscopy, solution state magnetic measurements, and DFT calculations. These studies were undertaken to compare the electronic structures of complexes $4 \mathbf{4 a}$ and $4 \mathrm{~b}$ to the reduced hydrosilylation catalyst ${ }^{\mathrm{dpp} B I A N F e}\left(\eta^{6}-\mathbf{C}_{7} \mathbf{H}_{8}\right)$. Full molecule DFT computational analysis for pre-catalysts $4 \mathbf{a}$ and $\mathbf{4 b}$, along with ${ }^{\mathrm{dpp}} \mathbf{B I A N F e}\left(\eta^{6}-\mathbf{C}_{7} \mathbf{H}_{8}\right)$, is 
presented below to elucidate the redox-activity of this ${ }^{\mathrm{dpp} B I A N}$ ligand in the catalyzed in situ hydrosilylation of 1-hexene with phenylsilane (vide infra).

\subsubsection{Spin state \& magnetism of bis(imino)acenaphthene iron dibromide complexes}

Zero-field ${ }^{57} \mathrm{Fe}$ Mössbauer spectra were collected and analyzed at $25 \mathrm{~K}, 100 \mathrm{~K}$, and 150 $\mathrm{K}$ for $\mathbf{4 a}$ and $25 \mathrm{~K}, 100 \mathrm{~K}$, and $200 \mathrm{~K}$ for $\mathbf{4 b}$ (Figure 7; Appendix A). The experimentally determined $(25 \mathrm{~K})$ isomer shifts $(\delta)$ and quadrupole splittings $\left(\left|\Delta E_{\mathrm{Q}}\right|\right)$ are reported in Table 3. Also reported in Table 3 are DFT-computed (vide infra) parameters for both compounds. It should be noted that varying the temperature for these zero-field ${ }^{57} \mathrm{Fe}$ Mössbauer studies did not produce any significant variation in isomer shifts or quadrupole splittings over the temperatures investigated. The isomer shifts $\left(0.88 \mathrm{~mm} \mathrm{~s}^{-1}\right)$ and quadrupole splittings $\left(2.73 \mathrm{~mm} \mathrm{~s}^{-1}(\mathbf{4 a}) ; 2.76\right.$ $\mathrm{mm} \mathrm{s}^{-1}(\mathbf{4 b})$ ) are nearly identical for $\mathbf{4 a}$ and $\mathbf{4 b}$, suggesting a similar electronic structure [23] consistent with a high spin iron(II) metal center $[16,24]$. This data compares favorably to the parameters of $\delta=0.84 \mathrm{~mm} \mathrm{~s}^{-1}$ and $\left|\Delta E_{\mathrm{Q}}\right|=2.67 \mathrm{~mm} \mathrm{~s}^{-1}$ reported by Wieghardt and coworkers for $\left[{ }^{\mathrm{dpp}} \mathrm{N}=\mathrm{C}(\mathrm{Me})-(\mathrm{Me}) \mathrm{C}=\mathrm{N}^{\mathrm{dpp}}\right] \mathrm{FeCl}_{2}$ [25]. Solution state magnetic moments were determined for both $\mathbf{4 a}$ and $\mathbf{4 b}$ by Evans' NMR method using a ferrocene standard and result from the average value of at least two independent measurements. The resulting magnetic measurements taken at $295 \mathrm{~K}$ provided effective magnetic moments of $4.8 \mu_{\mathrm{B}}(\mathbf{4 a})$ and $5.1 \mu_{\mathrm{B}}(\mathbf{4 b})$. These data are consistent with an $S=2$ ground state with a high spin Fe(II) center and a redox-neutral chelating $\left[{ }^{A r} \mathrm{BIAN}\right]^{0}$ ligand. 


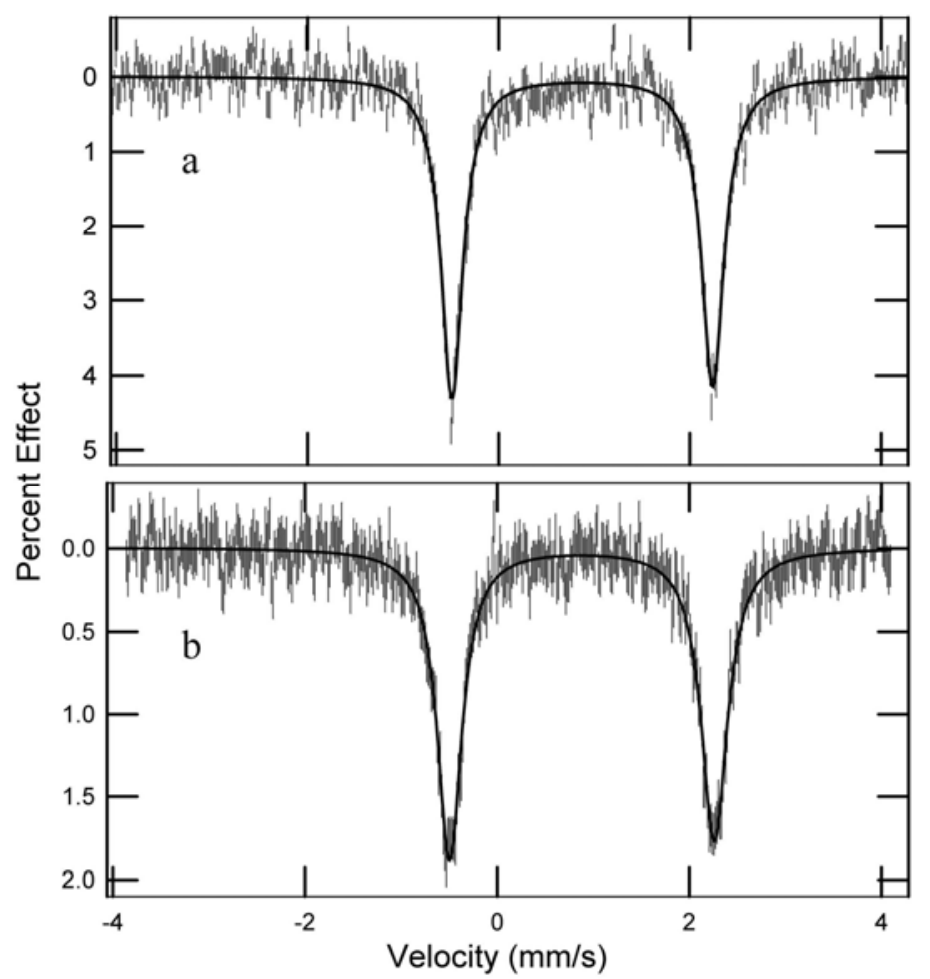

Figure 7. Mössbauer spectra including Lorentzian fits at $25 \mathrm{~K}$ for (a) $4 \mathbf{a}$ and (b) $\mathbf{4 b}$. See Appendix A for spectra recorded at higher temperatures.

Table 3. Comparison of experimental and computationally determined zero-field ${ }^{57} \mathrm{Fe}$ Mössbauer parameters ${ }^{\alpha}$

\begin{tabular}{ccc}
\hline compound & $\delta\left(\mathrm{mm} \mathrm{s}^{-1}\right)$ & $\left|\Delta E_{\mathrm{Q}}\right|\left(\mathrm{mm} \mathrm{s}^{-1}\right)$ \\
\hline${ }^{\mathrm{dpp} B} \mathrm{BIANFeBr}_{2}$ (4a) & 0.88 & 2.73 \\
& 0.79 & 2.52 \\
${ }^{{ }^{\mathrm{es}} \mathrm{BIANFeBr}_{2} \text { (4b) }}$ & 0.88 & 2.76 \\
& 0.80 & 2.64 \\
\hline
\end{tabular}

${ }^{\alpha}$ The experimental values were measured at $25 \mathrm{~K}$. Computed values are presented in italics.

\subsubsection{Quantum chemical computations}

Full molecule density functional theory (DFT) calculations on ${ }^{d p p} \mathrm{BIANFeBr}_{2}(\mathbf{4 a})$ and ${ }^{\text {Mes BIANFeBr}} 2$ (4b) were performed at the B3LYP level of theory to provide additional insight into the electronic structure description of these ${ }^{A r}$ BIAN iron dibromide complexes. The accuracy of the computations was assessed by comparison of the calculated and experimental metrical parameters (Table 2) along with the experimental and computed ${ }^{57} \mathrm{Fe}$ Mössbauer 
parameters (Table 3) for each compound (vide supra). On the basis of the magnetic data, two possible electronic structure models were computationally investigated that are consistent with the experimentally determined $S=2$ ground state for both complexes: (a) a high-spin Fe(II) center with a redox-innocent ligand $\left[{ }^{A r} \mathrm{BIAN}\right]^{0},\left(d^{6}, S_{\mathrm{Fe}}=2, S_{\mathrm{BIAN}}=0\right)$ and (b) a high spin Fe(III) center $\left(d^{5}, S_{\mathrm{Fe}}=5 / 2\right)$ antiferromagnetically coupled to a mono-reduced ligand bearing a delocalized radical anion $\left[{ }^{A r} \mathrm{BIAN}\right]^{1-}\left(S_{\mathrm{BIAN}}=-1 / 2\right)$. These electronic structure models were investigated with (a) a spin-unrestricted quintet (UKS) computational approach and (b) a broken symmetry (BS) approach denoted as $\mathrm{BS}(5,1)$, respectively. Ground state calculations at the B3LYP level of DFT were performed for both models, and in both complexes the computations converged to the appropriate UKS solution. That both approaches converged to the same solution indicates that a high spin $\mathrm{Fe}(\mathrm{II})$ center surrounded by a closed shell ligand, $\left[{ }^{A r} \mathrm{BIAN}\right]^{0}$, is the best description for the electronic structure of both compounds. The experimentally obtained, geometric metrical parameters were acceptably reproduced [26] by the spin-unrestricted computational model (Table 2). The computed Mössbauer isomer shifts and quadrupole splittings were also found to be within the generally accepted range established for these comparisons [27] to the experimental parameters (Table 3). Additionally, numerical frequency computations were performed at the same level of theory to confirm that a global energy minimum had been located and that there were no imaginary frequencies for both complexes. The agreement of the computed UKS parameters to those measured experimentally provides further support for the description of these complexes as high-spin ferrous centers supported by redox-innocent ${ }^{A r}$ BIAN ligands.

Qualitative molecular orbital diagrams and spin density plots of ${ }^{\mathrm{dpp} B I A N F e B r} 2$ and ${ }^{\mathrm{Mes}} \mathrm{BIANFeBr}_{2}$ derived from spin-unrestricted quintet model are depicted in Appendix A (4a) 
and Figure $8(\mathbf{4 b})$, respectively. The molecular orbital diagrams and spin density plots are remarkably similar, showing that the unpaired spins reside primarily on the high-spin ferrous center rather than on the ${ }^{A r}$ BIAN ligand. The spin density was calculated to be 3.68 a.u. for both complexes and is consistent with the majority of the spin density residing on the high spin iron(II) metal center with very minor contributions from the bromine and nitrogen atoms bound to the iron. The combined experimental and computational data establish that the ${ }^{A r}$ BIAN ligands are redox-innocent in these iron dibromide complexes. Taken together, these data provide a basis of comparison for other iron complexes supported by ${ }^{A r}$ BIAN ligands that behave in a redoxactive fashion.
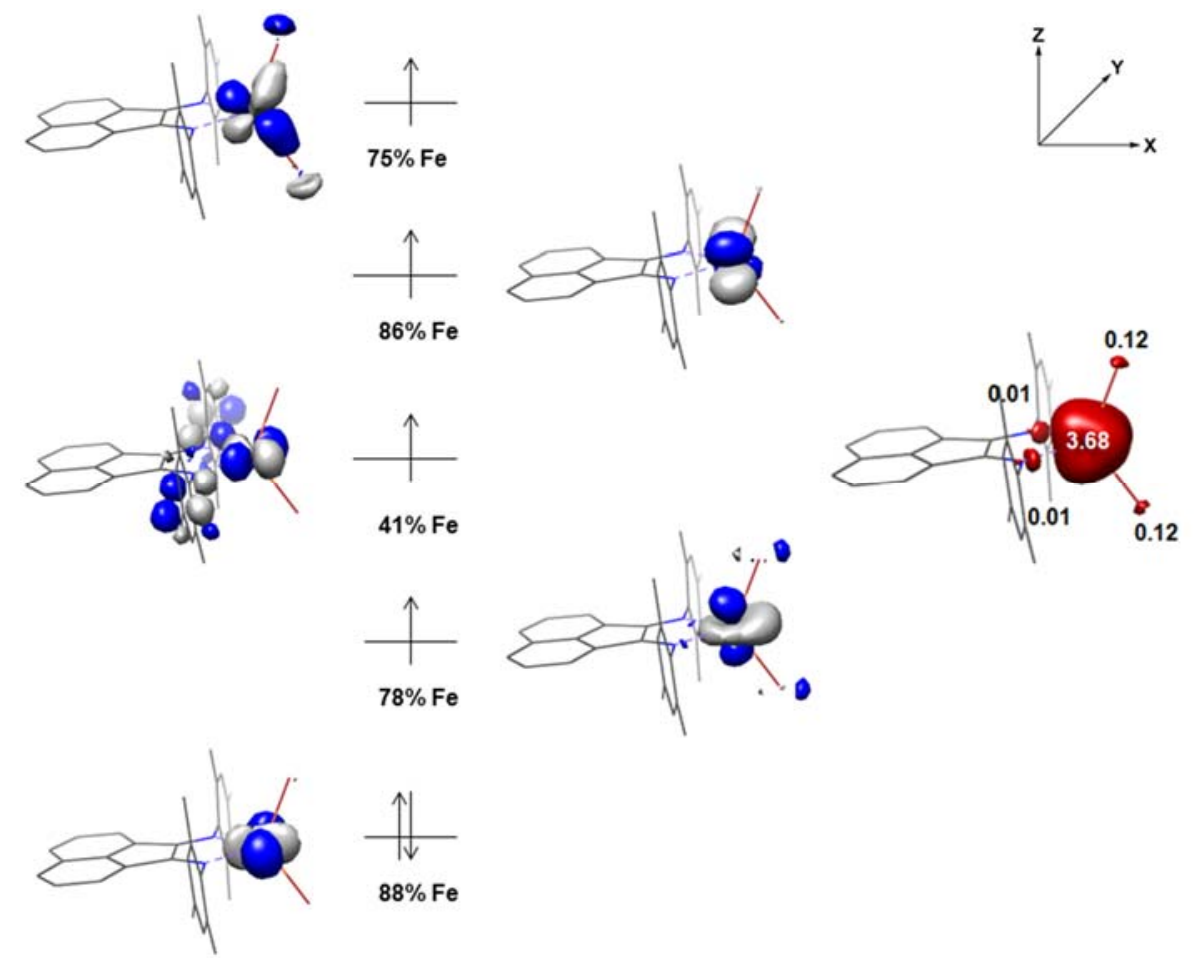

Figure 8. Qualitative molecular orbital diagram of $\mathbf{4 b}$ obtained from a spin-unrestricted (UKS) DFT calculation at the B3LYP level (left); spin density plot obtained from a Mulliken population analysis (right).

Two computational models were investigated for the experimentally determined singlet ground state of ${ }^{\mathrm{dpp}} \mathbf{B I A N F e}\left(\eta^{6}-\mathbf{C}_{7} \mathbf{H}_{8}\right)$ [12] using full molecule DFT calculations. A closed-shell 
spin-restricted (RKS) model, corresponding to a highly covalent, singlet ground state in which the BIAN ligand acts as a traditional $\pi$-acid, was explored. Additionally, because the experimentally determined ligand bond lengths are between those of $[\mathrm{BIAN} \cdot]^{1-}$ and $[\mathrm{BIAN}]^{2-}$, with a $\mathrm{C} \cdots \mathrm{C}$ distance of $1.400(4) \AA$ and a $\mathrm{C} \cdots \mathrm{N}$ distance of 1.343(3) $\AA$ [12], a spin-unrestricted $\mathrm{BS}(2,2)$ model was also examined. This model describes the $\left.{ }^{\mathrm{dpp}} \mathrm{BIAN}^{2-}\right) \mathrm{Fe}^{\mathrm{II}}\left(\eta^{6}-\mathrm{C}_{7} \mathrm{H}_{8}\right)$ ground state in which an intermediate-spin $\mathrm{Fe}^{\mathrm{II}}$ ion $\left(d^{6}, S_{\mathrm{Fe}}=1\right)$ antiferromagentically couples to a triplet diradical dianion $\left(S_{\mathrm{BIAN}}=-1\right)$.

Geometry optimizations were performed at the B3LYP level of theory on both models and produced two solutions. The broken-symmetry calculation converged to a BS(1,1) solution, which corresponds to a $\left.{ }^{\mathrm{dpp}} \mathrm{BIAN}^{1-}\right) \mathrm{Fe}^{\mathrm{I}}\left(\eta^{6}-\mathrm{C}_{7} \mathrm{H}_{8}\right)$ ground state in which a low-spin $\mathrm{Fe}^{\mathrm{I}}$ ion $\left(d^{7}, S_{\mathrm{Fe}}\right.$ $=1 / 2)$ antiferromagenetically couples with a $[\text { BIAN }]^{1-}$ radical anion $\left(S_{\text {BIAN }}=-1 / 2\right)$. Qualitative molecular orbital diagrams for the broken-symmetry and RKS solutions are presented in Figure 9 and Figure A.3.2 (Appendix A), respectively. In the BS(1,1) solution, the overlap between the two magnetic orbitals gives an overlap integral (S) of 0.54 , and results in a $5.4 \mathrm{kcal} / \mathrm{mol}$ energy stabilization relative to the RKS solution. The geometric parameters of the two solutions are presented in Table 4, and both reasonably reproduce the experimental values [12]. Interestingly, the RKS solution shows better agreement for the metal-ligand and intraligand distances.

To further distinguish between the two possible models, ${ }^{57} \mathrm{Fe}$ Mössbauer parameters were calculated for comparison with the experimental values $\left(\delta=0.45 \mathrm{~mm} / \mathrm{s},\left|\Delta E_{\mathrm{Q}}\right|=0.41 \mathrm{~mm} / \mathrm{s}\right)$ [12]. While the isomer shift obtained from the RKS solution $(\delta=0.46 \mathrm{~mm} / \mathrm{s})$ is in excellent agreement with the experimental results, the value obtained from the $\mathrm{BS}(1,1)$ solution $(\delta=0.61$ $\mathrm{mm} / \mathrm{s}$ ) is less accurate and outside the generally accepted range [27]. The quadrupole splitting $\left(\Delta E_{\mathrm{Q}}\right)$ is not acceptably reproduced by either the RKS or $\mathrm{BS}(1,1)$ solution, yielding values of 
1.51 and $-1.52 \mathrm{~mm} / \mathrm{s}$, respectively. As the high isomer shift obtained from the $\mathrm{BS}(1,1)$ solution is likely a result of the over estimation of the metal-ligand bond lengths, the broken-symmetry calculation was repeated using the experimentally obtained geometric parameters [12]. The isomer shift obtained from this calculation $(\delta=0.43 \mathrm{~mm} / \mathrm{s})$ acceptably reproduces the experimental value, while the quadrupole splitting $\left(\Delta E_{\mathrm{Q}}=-1.08 \mathrm{~mm} / \mathrm{s}\right)$ is still outside of the generally accepted range. Therefore, neither solution can be excluded on the basis of the Mössbauer parameter calculations. However, it is important to note that the RKS and BS(1,1) calculations yield asymmetry parameters of the electric field gradient, $\eta$, of 0.54 and 0.66 , respectively, indicating that applied field Mössbauer spectroscopy would allow for a more definitive electronic structure assignment. On the basis of the significant energy stabilization obtained from symmetry breaking [28], we favor the redox-active, $\left({ }^{\mathrm{dpp}} \mathrm{BIAN}^{1-}\right) \mathrm{Fe}^{\mathrm{I}}\left(\eta^{6}-\mathrm{C}_{7} \mathrm{H}_{8}\right)$ electronic structure description.

Table 4. Comparison of experimentally [12] and computationally determined geometric parameters $(\AA)$ for ${ }^{\text {dpp } B I A N F e}\left(\eta^{6}-\mathbf{C}_{7} \mathbf{H}_{8}\right)$.

\begin{tabular}{cccc}
\hline & Experimental [12] & RKS & BS(1,1) \\
\hline $\mathrm{C}^{\text {imine_C }}$ imine & $1.400(4)$ & 1.415 & 1.433 \\
$\mathrm{C}^{\text {imine}}-\mathrm{N}^{\text {imine }}$ & $1.343(3)$ & 1.347 & 1.338 \\
& $1.344(3)$ & 1.346 & 1.336 \\
$\mathrm{Fe}-\mathrm{N}^{\text {imine }}$ & $1.899(2)$ & 1.918 & 1.971 \\
& $1.903(2)$ & 1.917 & 1.973 \\
$\mathrm{Fe}-\mathrm{C}^{\mathrm{CH3}}$ & $2.104(3)$ & 2.156 & 2.190 \\
$\mathrm{Fe}-\mathrm{C}^{\text {ortho }}$ & $2.083(3)$ & 2.137 & 2.151 \\
& $2.080(3)$ & 2.142 & 2.145 \\
$\mathrm{Fe}-\mathrm{C}^{\text {meta }}$ & $2.083(3)$ & 2.124 & 2.136 \\
& $2.081(3)$ & 2.131 & 2.141 \\
$\mathrm{Fe}-\mathrm{C}^{\text {para }}$ & $2.082(3)$ & 2.115 & 2.156 \\
\hline
\end{tabular}




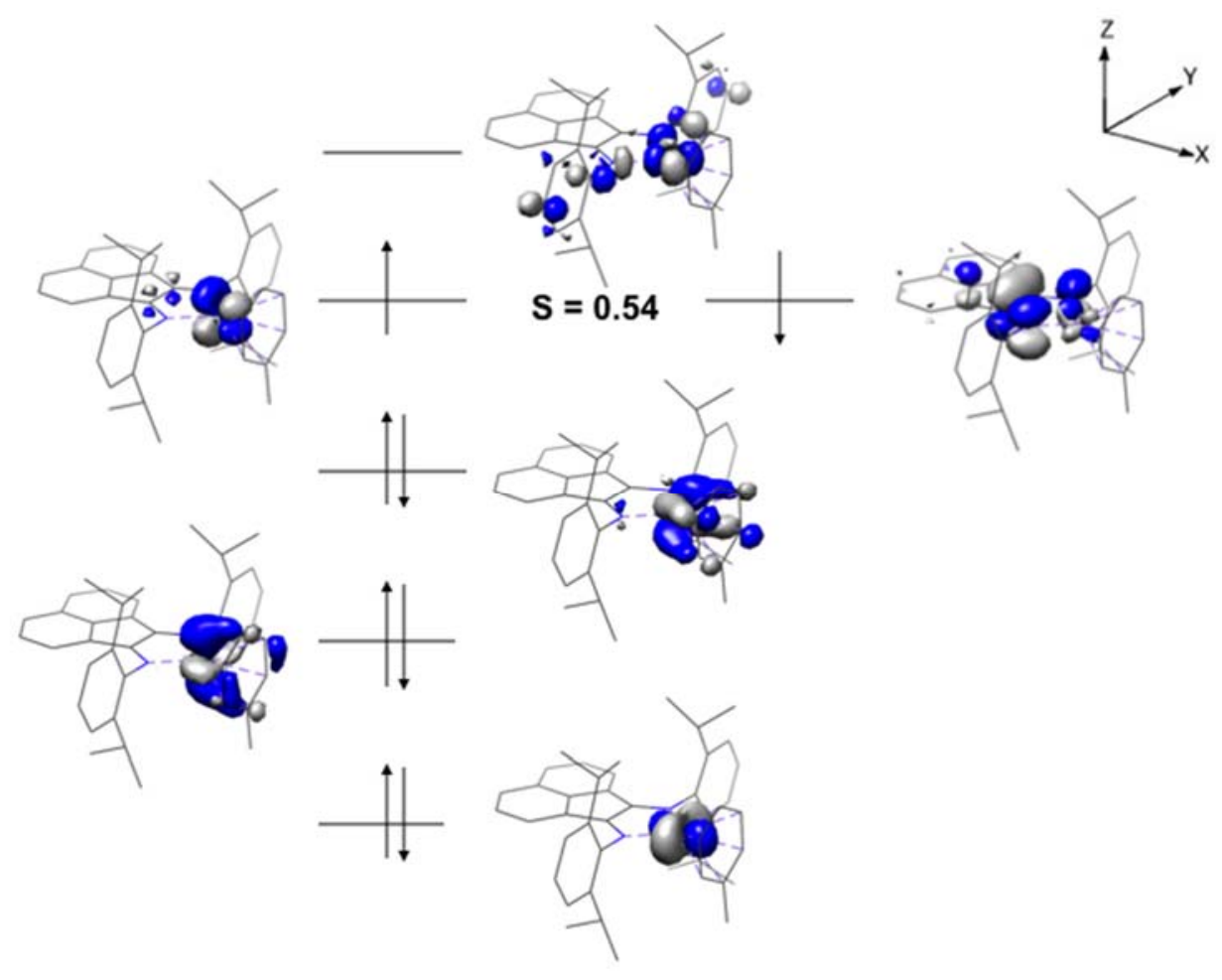

Figure 9. Qualitative molecular orbital diagram of ${ }^{d p p} \mathbf{B I A N F e}\left(\eta^{6}-\mathbf{C}_{7} \mathbf{H}_{8}\right)$ obtained from a $\mathrm{BS}(2,2)$ DFT calculation at the B3LYP level; this calculation converged to a BS $(1,1)$ solution.

\subsection{Catalytic hydrosilylation of 1-hexene with phenylsilane}

While bidentate $\alpha$-diimine ligands have yet to rival the tridentate PDI ligands for the support of highly active iron catalysts for industrially viable applications in hydrosilylation $[4,14]$, we hypothesized that the greater conjugation of ${ }^{A r}$ BIAN ligands may provide a more active iron catalyst than the parent $\alpha$-diimine ligands ${ }^{A r} \mathrm{~N}=\mathrm{C}(\mathrm{Me})-(\mathrm{Me}) \mathrm{C}=\mathrm{N}^{A r}$ in the hydrosilylation of a terminal alkene. As monoreduced $\left[{ }^{A r} \mathrm{PDI}\right]{ }^{1-}$ ligands have been proposed to play a role in stabilizing catalytic intermediates in related cycloisomerization reactions [29], we reasoned that the greater conjugation provided by the ${ }^{A r}$ BIAN ligand backbone may similarly stabilize catalytic intermediates bearing monoreduced $\left[{ }^{A r} \mathrm{BIAN}\right]^{1-}$ as compared to parent $\left[{ }^{A r} \mathrm{~N}=\mathrm{C}(\mathrm{Me})-(\mathrm{Me}) \mathrm{C}=\mathrm{N}^{A r}\right]^{1-}$ ligands. Thomas and co-workers have reported that solvent-free, in 
situ activation of pre-catalyst ${ }^{\mathrm{E}} \mathrm{PDIFeCl}_{2}(\mathrm{Et}=2,6$-diethylphenyl) with $n$-BuLi produced gramscale hydrosilylation of styrene with $\mathrm{Et}_{2} \mathrm{SiH}_{2}$ at ambient temperature in high yield [14].

Building upon the previous work of Thomas and coworkers [14], we developed an operationally simple iron-catalyzed hydrosilylation of 1-hexene in which reduced iron catalysts were generated in situ. To this end, $2.5 \mathrm{~mol} \%$ of iron pre-catalysts $\mathrm{LFeBr}_{2}(\mathbf{4 a}, \mathbf{4 b}, \mathbf{5 a}$, or $\mathbf{5 b}$ Figure 10) were activated in situ with $5 \mathrm{~mol} \% \mathrm{LiCH}_{2} \mathrm{SiMe}_{3}$ for $24 \mathrm{~h}$ in THF. After removing volatile materials in vacuo, neat substrates 1-hexene and $\mathrm{PhSiH}_{3}$ were added, and the 1-hexylphenylsilane product was isolated in high yield for pre-catalysts $4 \mathbf{a}(99 \%)$ and $\mathbf{5 a}(95 \%)$ and low yield for pre-catalysts $\mathbf{4 b}(16 \%)$ and $\mathbf{5 b}(37 \%)$. The isolated yields reported in Figure 10 were determined by ${ }^{1} \mathrm{H}$ NMR spectroscopy upon comparison of product integration intensities to an external standard of 1,3,5-trimethoxybenzene [14]. Of the four pre-catalysts investigated, 4a produced the highest yield with a turnover number (TON) of 10 .
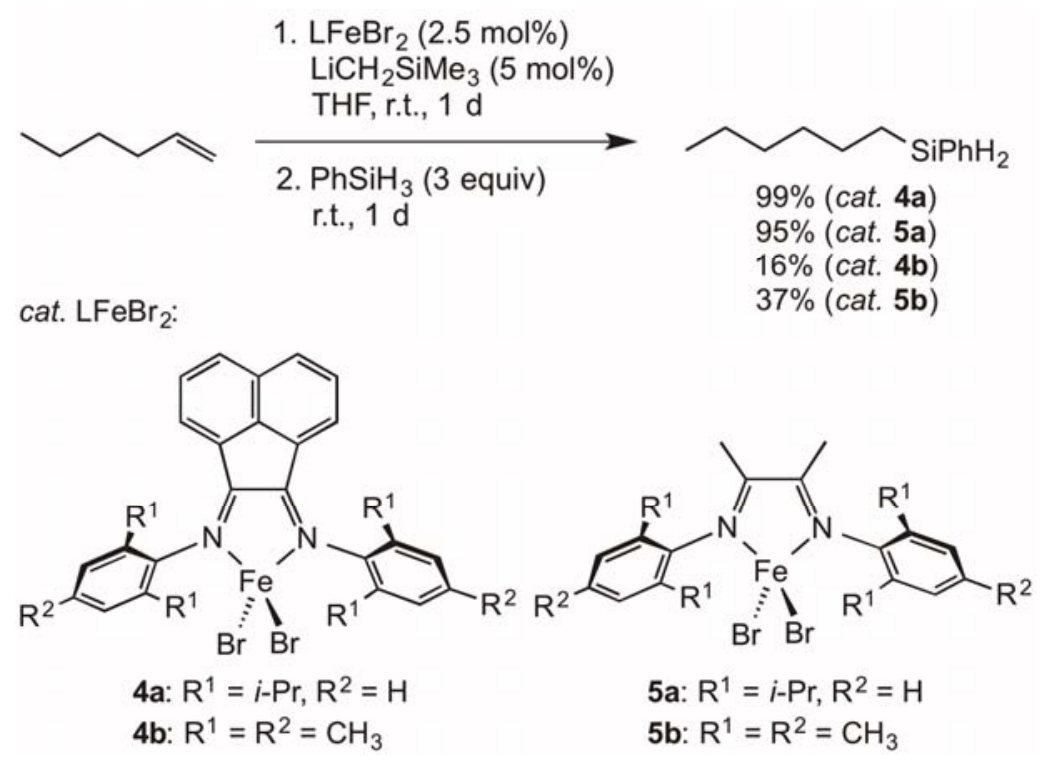

Figure 10. Catalytic hydrosilylation of 1-hexene with phenylsilane at ambient temperature upon in situ activation of pre-catalysts $\mathbf{4 a} / \mathbf{b}$ and $\mathbf{5 a} / \mathbf{b}$ with $\mathrm{LiCH}_{2} \mathrm{SiMe}_{3}$. 
Given the higher yields for pre-catalyst $\mathbf{4 a}$, we sought to further optimize these conditions by decreasing catalyst loading and exploring alternate reducing agents. To further optimize this method, 1 mol\% pre-catalyst 4 a was reduced in situ with $2 \mathrm{~mol} \% \mathrm{LiCH}_{2} \mathrm{SiMe}_{3}$ activator in THF, and this was found to catalyze the solvent-free hydrosilylation of 1-hexene (1 equiv) with phenylsilane (1 equiv), producing 1-hexylphenylsilane in a 95\% yield after $24 \mathrm{~h}$ at ambient temperature with an improved TON of 48. Several different activators were investigated for this method by measuring the ${ }^{1} \mathrm{H}$ NMR yield of 1-hexylphenylsilane following the conditions described in Figure 10, including EtMgBr (3\%), NaHBEt3 (12\%), and in situ-generated sodium naphthalenide (24\%). However, when the activation solvent used was toluene, the yield of 1hexylphenylsilane was $99 \%$ with in situ-generated sodium naphthalenide as the reducing agent, notably identical to the best conditions presented in Figure 10 with the $\mathrm{LiCH}_{2} \mathrm{SiMe}_{3}$ reducing agent. This suggests that both reducing agents may be forming the same active catalyst. The crude activated catalyst mixture, resulting from the addition of 2 equiv of sodium napthalenide to 4a in toluene for $24 \mathrm{~h}$, was analyzed by ${ }^{1} \mathrm{H}$ NMR spectroscopy in $\mathrm{C}_{6} \mathrm{D}_{6}$, demonstrating that

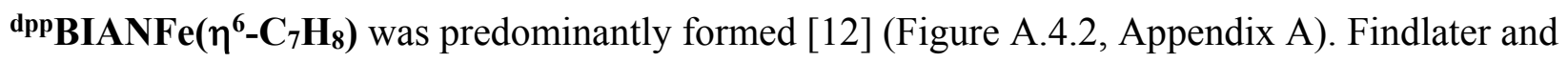
coworkers have demonstrated that isolated ${ }^{\mathrm{dpp}} \mathbf{B I A N F e}\left(\eta^{6}-\mathbf{C}_{7} \mathbf{H}_{8}\right)$ effectively catalyzes the hydrosilylation of ketones and aldehydes at elevated temperature $\left(70^{\circ} \mathrm{C}\right)[12]$, while Chirik and coworkers have shown that isolated $\mathrm{PDIFe}\left(\mathrm{CH}_{2} \mathrm{SiMe}_{3}\right)_{2}$ complexes successfully catalyze the hydrosilylation of olefins at elevated temperatures of $60{ }^{\circ} \mathrm{C}$ [5]. Presumably, ${ }^{\mathrm{dpp}} \mathbf{B I A N F e}\left(\eta^{6}-\right.$ $\mathbf{C}_{7} \mathbf{H}_{8}$ ) would undergo dissociation of the $\eta^{6}$-toluene ligand while proposed

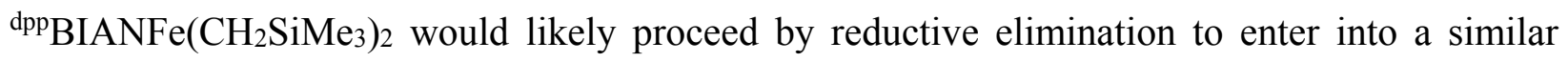
catalytic cycle. 
Comparison of the yields shown in Figure 10 may indicate certain features of the bidentate $\alpha$-diimine pre-catalysts that promote enhanced activity. The $N$-substituents appear to play a significant role in the activity of these $\alpha$-diimine iron catalysts, as the dpp substituents of 4a and 5a presumably lead to significantly higher activity than the $N$-Mes substituents for $\mathbf{4 b}$ and 5b. This observed lower activity for $\mathbf{4 b}$ in particular may be attributed to the in situ formation of stable, ligated iron complexes such as $\mathbf{4 b}$.THF (vide supra), which may inhibit pre-catalyst activation and/or catalytic turnover. As pre-catalyst 4a produced 1-hexyl-phenylsilane in a higher yield than did pre-catalyst 5a under similar reaction conditions, the more conjugated backbone of

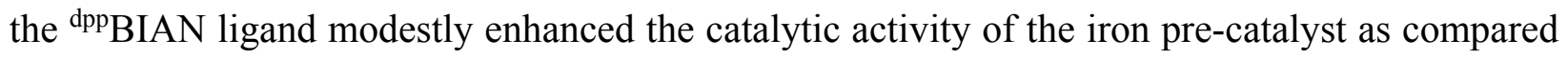
to the ${ }^{\mathrm{dpp}} \mathrm{N}=\mathrm{C}(\mathrm{Me})-(\mathrm{Me}) \mathrm{C}=\mathrm{N}^{\mathrm{dpp}}$ ligand. This suggests that $\left[{ }^{\mathrm{dpp}} \mathrm{BIAN}\right]^{1-} \mathrm{Fe}^{\mathrm{I}}$ intermediates may be relatively stabilized compared to $\left[{ }^{\mathrm{dpp}} \mathrm{N}=\mathrm{C}(\mathrm{Me})-(\mathrm{Me}) \mathrm{C}=\mathrm{N}^{\mathrm{dpp}}\right]^{1-} \mathrm{Fe}^{\mathrm{I}}$ intermediates due to increased conjugation of the ${ }^{\mathrm{dpp}} \mathrm{BIAN}$ backbone. It should be noted that $\left[{ }^{\mathrm{dpp}} \mathrm{BIAN}\right]^{2-} \mathrm{Fe}^{\mathrm{II}}$ catalytic intermediates would likely be relatively destabilized by the $10 \pi$ electrons $(2 n)$ of the BIAN $^{2-}$ ene-diamide form of the ligand (Figure 2) as compared to possible $\left[{ }^{\mathrm{dpp}} \mathrm{N}=\mathrm{C}(\mathrm{Me})-(\mathrm{Me}) \mathrm{C}=\mathrm{N}^{\mathrm{dpp}}\right]^{2-}$ $\mathrm{Fe}^{\mathrm{II}}$ intermediates, suggesting that the ene-diamide forms of these ligands are less likely to play a significant role in stabilizing key catalytic intermediates. Overall, the $N$-dpp substituent leads to

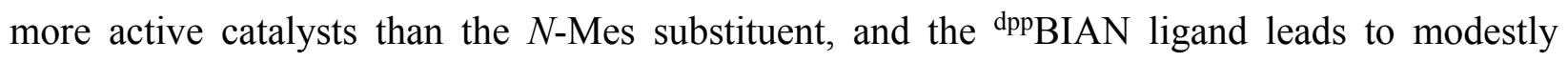
higher catalytic activity of iron complexes in the hydosilylation of 1-hexene with $\mathrm{PhSiH}_{3}$ as compared to the parent $\alpha$-diimine ligand.

\section{Conclusions}

Anhydrous iron dibromide complexes $(\mathbf{4 a}, \mathbf{4 b}, \mathbf{5 a}, \mathbf{5 b})$ bearing bidentate $\alpha$-diimine ligands have been prepared and characterized by ${ }^{1} \mathrm{H}$ NMR spectroscopy. The aryl-substituted 
BIAN complexes $\mathbf{4 a}$ and $\mathbf{4 b}$ were structurally characterized by single-crystal $\mathrm{X}$-ray diffraction, and their metrical parameters are consistent with a redox innocent $\left[{ }^{A r} \mathrm{BIAN}\right]^{0}$ chelating ligand for both complexes. High-spin iron(II) electronic structure descriptions for the $\mathbf{4 a}$ and $\mathbf{4 b}{ }^{A r} \mathrm{BIAN}$ iron pre-catalysts are supported by Mössbauer spectroscopy, solution state magnetic measurements indicating an $S=2$ ground state, and DFT quantum-chemical calculations. Upon in situ reduction with $\mathrm{LiCH}_{2} \mathrm{SiMe}_{3}$, the iron complexes promote catalytic hydrosilylation of 1hexene with phenylsilane at ambient temperature, with highest yields provided by pre-catalyst

${ }^{\mathrm{dpp} B I A N F e B r} 2$ (4a) followed closely by parent $\alpha$-diimine pre-catalyst 5a. The smaller $N$ substituents for ${ }^{\mathrm{Mes}} \mathrm{BIANFeBr}_{2}(\mathbf{4 b})$ and parent $\alpha$-diimine pre-catalyst $\mathbf{5 b}$ may lead to the formation of less active iron complexes with a higher coordination number. In situ reduction of 4a with sodium naphthalenide produced ${ }^{\mathrm{dpp}} \mathbf{B I A N F e}\left(\eta^{6}-\mathbf{C}_{7} \mathbf{H}_{8}\right)$, and this also promoted successful hydrosilylation. DFT computational analysis of ${ }^{d p p} \mathbf{B I A N F e}\left(\eta^{6}-\mathbf{C}_{7} \mathbf{H}_{8}\right)$ suggests a redox-active, $\left({ }^{\mathrm{dpp}} \mathrm{BIAN}^{1-}\right) \mathrm{Fe}^{\mathrm{I}}\left(\eta^{6}-\mathrm{C}_{7} \mathrm{H}_{8}\right)$ electronic structure description. Future studies focus on defining the substrate scope for $\alpha$-diimine- and ${ }^{A r}$ BIAN-supported iron-catalyzed olefin hydrosilylation reactions.

\section{Experimental}

\subsection{General considerations}

All air- and moisture-sensitive manipulations were carried out using standard vacuum line and Schlenk techniques or in a Vacuum Atmospheres inert (purified nitrogen) atmosphere glovebox. Glassware was dried overnight at $150{ }^{\circ} \mathrm{C}$ or flame dried under vacuum immediately prior to use. Celite, sieves, and other solid supports were dried in an oven for 1 week at $150{ }^{\circ} \mathrm{C}$ and were then further dried under vacuum at $150{ }^{\circ} \mathrm{C}$ for $24 \mathrm{~h}$. Solvents for air- and moisture- 
sensitive manipulations were dried and deoxygenated either using a Vacuum Atmospheres Solvent Purification System or were vacuum transferred from $\mathrm{CaH}_{2}$ and deoxygenated using freeze-pump-thaw methods. Deuterated solvents (Cambridge Isotope Laboratories), 1-hexene (Sigma-Aldrich), and phenylsilane (Sigma-Aldrich) were either deoxygenated using freezepump-thaw methods and dried over $4 \mathrm{~A}$ molecular sieves, or were dried over $\mathrm{CaH}_{2}$ (SigmaAldrich) and then vacuum transferred and deoxygenated using freeze-pump-thaw methods prior to use [30]. Iron(II)bromide, acenaphthenquinone, 2,3-butanedione, 2,6-diisopropylaniline, and 2,4,6-trimethylaniline were purchased from Sigma-Aldrich and were used as received. Formic acid was purchased from Flinn Scientific and was used as received. Ferrocene (Sigma-Aldrich) was sublimed under reduced pressure prior to use. A $1.0 \mathrm{M}$ solution of $\mathrm{LiCH}_{2} \mathrm{SiMe}_{3}$ in pentane (Sigma-Aldrich) was crystallized at $-10{ }^{\circ} \mathrm{C}$ prior to use.

${ }^{1} \mathrm{H}$ and ${ }^{13} \mathrm{C}$ NMR spectra were recorded on a Bruker Avance III $400 \mathrm{MHz}$ spectrometer. All ${ }^{1} \mathrm{H}$ chemical shifts $(\delta)$ are reported relative to $\mathrm{SiMe}_{4}$ using the ${ }^{1} \mathrm{H}$ (residual) shift of the solvent as a secondary standard. Peak width at half height is given for paramagnetically broadened resonances. Solution magnetic moments were determined by Evans' NMR method [31] using a ferrocene standard and result from the average value of at least two independent measurements. ${ }^{13} \mathrm{C}\left\{{ }^{1} \mathrm{H}\right\}$ NMR chemical shifts $(\delta)$ are reported in ppm relative to the carbon resonance of the deuterated solvent. Infrared (IR) spectra were taken as $\mathrm{KBr}$ films using a PerkinElmer FTIR Spectrometer model FRONTIER MIR +SP10 STD. Elemental analyses were performed by Robertson Microlit Laboratories, Inc., in Madison, NJ. Melting points were measured in flame-sealed capillary tubes under a static vacuum using a Mel-Temp II. 


\subsection{Preparation of $\alpha$-diimine ligands}

Preparation of the ${ }^{A r}$ BIAN ligands followed analogous literature procedures to those described in the literature $[12,15]$ by acid-catalyzed condensation of the respective anilines with acenaphthenequinone and were recrystallized from EtOH. The ${ }^{1} \mathrm{H}$ and ${ }^{13} \mathrm{C}$ NMR data for

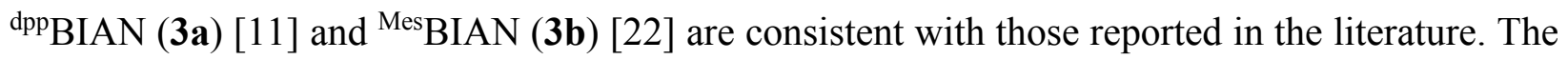

$\alpha$-diimine ligands ${ }^{\text {dpp }} \mathrm{N}=\mathrm{C}(\mathrm{Me})-\mathrm{C}(\mathrm{Me})=\mathrm{N}^{\mathrm{dpp}}[9,32]$ and ${ }^{\mathrm{Mes}} \mathrm{N}=\mathrm{C}(\mathrm{Me})-\mathrm{C}(\mathrm{Me})=\mathrm{N}^{\mathrm{Mes}}$ [17] were prepared according to literature procedures.

\subsubsection{Preparation of bis $\left[N, N^{\prime}-(2,6\right.$-diisopropylphenyl)imino] acenaphthene (dpp BIAN, 3a)}

To a slurry of acenapthenequinone (1) $(9.386 \mathrm{~g}, 51.5 \mathrm{mmol})$ and formic acid $(1.0 \mathrm{~mL})$ in ethanol (700 mL) was added 2,6-diisopropylaniline (2a) $(19.75 \mathrm{~mL}, 104.7 \mathrm{mmol})$ in ethanol (200 $\mathrm{mL}$ ) dropwise over 7 days at $65{ }^{\circ} \mathrm{C}$. The reaction mixture was cooled to ambient temperature and the orange solid was collected by vacuum filtration. The remaining ethanol solution was concentrated in vacuo and cooled to $-12{ }^{\circ} \mathrm{C}$ to give crystallized 3a (23.36 g, 91\%); ${ }^{1} \mathrm{H}$ NMR (400 $\left.\mathrm{MHz}, \mathrm{CDCl}_{3}\right): \delta 7.86$ (d, $\left.J=8.3 \mathrm{~Hz}, 2 \mathrm{H}, \mathrm{Ar}_{\mathrm{acen}}\right), 7.36$ (t, $\left.J=7.8 \mathrm{~Hz}, 2 \mathrm{H}, \mathrm{Ar}_{\mathrm{acen}}\right), 7.3-7.2(\mathrm{~m}, 6 \mathrm{H}$, $A r), 6.64(\mathrm{~d}, J=7.3 \mathrm{~Hz}, 2 \mathrm{H}, A r), 3.03$ (sept, $J=6.9 \mathrm{~Hz}, 4 \mathrm{H}, \mathrm{C} H \mathrm{Me} 2), 1.24(\mathrm{~d}, J=6.9 \mathrm{~Hz}, 12 \mathrm{H}$, $\mathrm{MeCHMe}), 0.98(\mathrm{~d}, J=6.9 \mathrm{~Hz}, 12 \mathrm{H}, \mathrm{MeCHMe}) ;{ }^{13} \mathrm{C}\left\{{ }^{1} \mathrm{H}\right\}$ NMR $\left(100 \mathrm{MHz}, \mathrm{CDCl}_{3}\right): \delta 160.99$, $147.51,140.82,135.44,131.12,129.51,128.89,127.89,124.30,123.48,123.36,28.63$ (MeCHMe), 23.44 (MeCHMe), 23.15 (MeCHMe); IR, $v / \mathrm{cm}^{-1}:$ 3065, 2961, 2925, 2867, 1668, $1590,1466,1455,1428$.

\subsubsection{Preparation of bis $\left[N, N^{\prime}-(2,4,6\right.$-trimethylphenyl)imino] acenaphthene (Mes $B I A N, 3 \boldsymbol{b})$}

To a slurry of acenapthenequinone (1) $(5.801 \mathrm{~g}, 31.84 \mathrm{mmol})$ and formic acid $(1.0 \mathrm{~mL})$ in ethanol $(400 \mathrm{~mL})$ was added 2,4,6-trimethylaniline $(\mathbf{2 b})(9.00 \mathrm{~mL}, 64.1 \mathrm{mmol})$ in ethanol $(200$ 
$\mathrm{mL}$ ) dropwise over 6 days at $65^{\circ} \mathrm{C}$. The resulting mixture was cooled to ambient temperature and the solid was collected by vacuum filtration. The remaining solution was concentrated in vacuo, cooled to $-12{ }^{\circ} \mathrm{C}$ for crystallization, and then vacuum filtered to collect $\mathbf{3 b}(9.512 \mathrm{~g}, 72 \%)$ as an red-orange solid; ${ }^{1} \mathrm{H} \mathrm{NMR}\left(400 \mathrm{MHz}, \mathrm{CDCl}_{3}\right): \delta 7.87(\mathrm{~d}, J=8.3 \mathrm{~Hz}, 2 \mathrm{H}), 7.4-7.3(\mathrm{~m}, 2 \mathrm{H})$, 6.98 (s, 4H, m-Ar), 6.79 (d, $J=7.2 \mathrm{~Hz}, 2 \mathrm{H}), 2.38$ (s, 6H, $p-M e-\mathrm{Ar}$ ), 2.11 (s, 12H,o-Me-Ar); ${ }^{13} \mathrm{C}\left\{{ }^{1} \mathrm{H}\right\}$ NMR (100 MHz, $\left.\mathrm{CDCl}_{3}\right): \delta 161.12,146.83,140.58,132.84,131.04,129.74,128.97$, 128.82, 128.26, 124.63, 122.51, 20.98, 17.76; IR, $v / \mathrm{cm}^{-1}: 2966,2941,2908,2851,1673,1647$, $1601,1593,1472,1420,1437$.

\subsection{Preparation of iron compounds}

4.3.1. Preparation of bis[N,N'-(2,6-diisopropylphenyl)imino]acenaphthene iron(II) bromide $\left({ }^{d p p} B I A N F e B r 2,4 a\right)$

In an inert atmosphere glovebox, a solution of ${ }^{\mathrm{dpp}} \operatorname{BIAN}(\mathbf{3 a})(3.426 \mathrm{~g}, 6.846 \mathrm{mmol})$ and $\mathrm{FeBr}_{2}(1.529 \mathrm{~g}, 7.090 \mathrm{mmol})$ in THF $(100 \mathrm{~mL})$ was stirred for 3 days at ambient temperature. The solution was then filtered through celite to remove any insoluble material and the volatile materials were removed under vacuum to afford $4 \mathbf{a}(4.654 \mathrm{~g}, 95 \%)$ as a dark green solid. Crystals suitable for X-ray diffraction analysis were obtained by cooling a solution of $\mathbf{4 a}$ in $\mathrm{CH}_{2} \mathrm{Cl}_{2}$ to $-32{ }^{\circ} \mathrm{C}$; mp $350-351{ }^{\circ} \mathrm{C} ;{ }^{1} \mathrm{H}$ NMR $\left(400 \mathrm{MHz}, \mathrm{CD}_{2} \mathrm{Cl}_{2}\right) \delta 13.64\left(42 \mathrm{~Hz}, 2 \mathrm{H}, \mathrm{Ar}_{\text {acen }}\right), 7.38$ (54 Hz, 4H, m-Ar), $3.02(27 \mathrm{~Hz}, 2 \mathrm{H}, \mathrm{Ar}$ acen), $2.77(44 \mathrm{~Hz}, 12 \mathrm{H}, \mathrm{MeCHMe}), 2.13(83 \mathrm{~Hz}, 2 \mathrm{H}$, Aracen), -4.02 (118 Hz, 12H, MeCHMe), -16.65 (52 Hz, 2H, p-Ar), one peak not located; Magnetic susceptibility (Evans' Method, $295 \mathrm{~K}$ ): $\mu_{\mathrm{eff}}=4.8(3) \mu_{\mathrm{B}}$; IR $(\mathrm{KBr}), v / \mathrm{cm}^{-1}: 3066,2962$, 2927, 2868, 1643, 1614, 1597, 1576, 1436, 1420; Anal. Calcd for $\mathrm{C}_{36} \mathrm{H}_{40} \mathrm{Br}_{2} \mathrm{FeN}_{2}$ : C, 60.36; H, 5.63; N, 3.91. Found: C, 59.95; H, 5.91; N, 4.11; Mössbauer data were collected at 25 K, 100 K, and $150 \mathrm{~K}$ (Appendix A, Figure A.2.1). 


\subsubsection{Preparation of bis[N,N'-(2,4,6-trimethylphenyl)imino]acenaphthene iron(II) bromide}

(Mes BIANFeBr $2, \mathbf{4} \boldsymbol{b})$

In an inert atmosphere glovebox, a solution of ${ }^{\mathrm{Mes}} \operatorname{BIAN}(\mathbf{3 b})(1.000 \mathrm{~g}, 2.401 \mathrm{mmol})$ and $\mathrm{FeBr}_{2}(0.518 \mathrm{~g}, 2.402 \mathrm{mmol})$ in $\mathrm{CH}_{2} \mathrm{Cl}_{2}(20 \mathrm{~mL})$ was stirred for 2 days at ambient temperature. The solution was then filtered through celite to remove any insoluble material and the volatile materials were removed under vacuum to afford ${ }^{\mathrm{Mes}} \mathrm{BIANFeBr}_{2}(\mathbf{4 b})(1.136 \mathrm{~g}, 75 \%)$ as a dark red/brown powder. Crystals suitable for X-ray diffraction analysis were obtained by cooling a solution of $\mathbf{4 b}$ in $\mathrm{CH}_{2} \mathrm{Cl}_{2}$ to $-32{ }^{\circ} \mathrm{C}$; mp $355-357{ }^{\circ} \mathrm{C}$; Magnetic susceptibility (Evans' Method, $295 \mathrm{~K}): \mu_{\mathrm{eff}}=5.0(6) \mu \mathrm{B} ;{ }^{1} \mathrm{H}$ NMR (400 MHz, $\left.\mathrm{CD}_{2} \mathrm{Cl}_{2}\right) \delta 16.18(4 \mathrm{~Hz}, 6 \mathrm{H}, p-M e-\mathrm{Ar}), 14.92(17$ $\mathrm{Hz}, 2 \mathrm{H}, \mathrm{Ar} a c e n), 11.18(189 \mathrm{~Hz}, 12 \mathrm{H}, o-M e-\mathrm{Ar}), 5.93(19 \mathrm{~Hz}, 4 \mathrm{H}, m-\mathrm{Ar}), 0.46(16 \mathrm{~Hz}, 2 \mathrm{H}$, Aracen), 0.06 (40 Hz, 2H, Aracen); IR (KBr), v/cm ${ }^{-1}: 3014,2945,2915,2860,1653,1622,1602$, 1585, 1478, 1419, 1386, 1356; Anal. Calcd for $\mathrm{C}_{30} \mathrm{H}_{28} \mathrm{Br}_{2} \mathrm{FeN}_{2}$ : C, 56.99; H, 4.46; N, 4.43. Found: C, 56.72; H, 4.49; N, 4.35; Mössbauer data were collected at $25 \mathrm{~K}, 100 \mathrm{~K}$, and $200 \mathrm{~K}$ (Appendix A, Figure A.2.2).

\subsubsection{Preparation of $\quad\left[{ }^{d p p} N=C(M e)-C(M e)=N^{d p p}\right] \quad$ iron(II) $\quad$ bromide $\quad\left(\left[{ }^{d p p} N=C(M e)\right.\right.$ -} $\left.\left.C(M e)=N^{d p p}\right] F e B r 2,5 a\right)$

This procedure follows that described in the literature for the analogous iron dichloride complex $\left[{ }^{\mathrm{dpp}} \mathrm{N}=\mathrm{C}(\mathrm{Me})-\mathrm{C}(\mathrm{Me})=\mathrm{N}^{\mathrm{dpp}}\right] \mathrm{FeCl}_{2}$ [9]. In an inert atmosphere glovebox, a solution of ligand ${ }^{d p p} \mathrm{~N}=\mathrm{C}(\mathrm{Me})-\mathrm{C}(\mathrm{Me})=\mathrm{N}^{\mathrm{dpp}}[9,32](1.617 \mathrm{~g}, 4.00 \mathrm{mmol})$ and $\mathrm{FeBr}_{2}(0.893 \mathrm{~g}, 4.14 \mathrm{mmol})$ in THF $(50 \mathrm{~mL})$ was stirred for 3 days at ambient temperature. The solution was then filtered through celite to remove any insoluble material and the volatile materials were removed under vacuum to afford 5a $(2.234 \mathrm{~g}, 90 \%)$ as a dark blue powder; $\mathrm{mp} 345-346{ }^{\circ} \mathrm{C} ;{ }^{1} \mathrm{H} \mathrm{NMR}(400 \mathrm{MHz}$, 
$\left.\mathrm{CD}_{2} \mathrm{Cl}_{2}\right) \delta 74.37(165 \mathrm{~Hz}, 6 \mathrm{H}, \mathrm{CimMe}), 5.64(28 \mathrm{~Hz}, 4 \mathrm{H}, m-\mathrm{Ar}), 3.70(42 \mathrm{~Hz}, 12 \mathrm{H}, \mathrm{MeCHMe}),-$ $5.75(100 \mathrm{~Hz}, 12 \mathrm{H}, \mathrm{MeCHMe}),-18.53(21 \mathrm{~Hz}, 2 \mathrm{H}, p-\mathrm{Ar})$, one peak not located; IR (KBr), v/cm ${ }^{-}$ 1: $3062,2964,2924,2867,1631,1587,1542,1464,1442,1374,1324,1291$; Anal. Calcd for $\mathrm{C}_{28} \mathrm{H}_{40} \mathrm{Br}_{2} \mathrm{FeN}_{2}$ : C, 54.22; H, 6.50; N, 4.52. Found: C, 54.48; H, 6.51; N, 4.48.

4.3.4. Preparation of $\quad\left[{ }^{\mathrm{Mes}} N=C(\mathrm{Me})-C(\mathrm{Me})=N^{\text {Mes }}\right] \quad$ iron(II) $\quad$ bromide $\quad\left(\left[{ }^{\mathrm{Mes}} N=C(\mathrm{Me})\right.\right.$ $\left.\left.C(M e)=N^{M e s}\right] F e B r 2,5 \boldsymbol{b}\right)$

In an inert atmosphere glovebox, a solution of ligand ${ }^{\mathrm{Mes}} \mathrm{N}=\mathrm{C}(\mathrm{Me})-\mathrm{C}(\mathrm{Me})=\mathrm{N}^{\mathrm{Mes}}[17]$ (5.357 g, $16.72 \mathrm{mmol})$ and $\mathrm{FeBr}_{2}(3.605 \mathrm{~g}, 16.72 \mathrm{mmol})$ in $\mathrm{CH}_{2} \mathrm{Cl}_{2}(50 \mathrm{~mL})$ was stirred for 1 day at ambient temperature. The solution was then filtered to remove any insoluble material and the volatile materials were removed under vacuum to afford $\mathbf{5 b}(8.466 \mathrm{~g}, 95 \%)$ as a dark green powder; mp 286-287 ${ }^{\circ} \mathrm{C} ;{ }^{1} \mathrm{H}$ NMR (400 MHz, $\left.\mathrm{CD}_{2} \mathrm{Cl}_{2}\right) \delta 118.20\left(131 \mathrm{~Hz}, 6 \mathrm{H}, \mathrm{C}_{\mathrm{im}} M e\right), 15.36(4$ Hz, 6H, p-Me-Ar), 7.53 (184 Hz, 12H, o-Me-Ar), 2.55 (20 Hz, 4H, m-Ar); IR (KBr), v/cm ${ }^{-1}$ : 2080, 1819, 1774, 1740, 1629, 1378, 1290, 1222, 1158; Anal. Calcd for $\mathrm{C}_{22} \mathrm{H}_{28} \mathrm{Br}_{2} \mathrm{FeN}_{2}: \mathrm{C}$, 49.29; H, 5.26; N, 5.23. Found: C, 49.34; H, 5.27; N, 5.24.

\subsection{Representative procedure for catalytic hydrosilylation}

To a mixture of pre-catalyst ${ }^{\mathrm{dpp}} \mathrm{BIANFeBr}_{2}(\mathbf{4 a})(0.150 \mathrm{~g}, 0.209 \mathrm{mmol})$ in THF (3 mL), a solution of $\mathrm{LiCH}_{2} \mathrm{SiMe}_{3}(0.039 \mathrm{~g}, 0.42 \mathrm{mmol})$ in THF $(3 \mathrm{~mL})$ was added dropwise with stirring, and the reaction mixture was allowed to stir for $24 \mathrm{~h}$ at ambient temperature in an inert atmosphere glovebox. After the volatile materials were removed in vacuo, phenylsilane (0.76 $\mathrm{mL}, 6.2 \mathrm{mmol})$ and 1-hexene $(0.26 \mathrm{~mL}, 2.1 \mathrm{mmol})$ were added and the reaction mixture was allowed to stir for $24 \mathrm{~h}$ at rt. The reaction mixture was then exposed to air, extracted with $n$ - 
pentane $(10 \mathrm{~mL})$, filtered through Celite $(3 \mathrm{~cm}$ pipet column), and the volatile materials were removed in vacuo. The organic residue was then dissolved in $\mathrm{C}_{6} \mathrm{D}_{6}$, and 1,3,5-trimethoxybenzene (0.0235 g, $0.140 \mathrm{mmol})$ was added as a ${ }^{1} \mathrm{H}$ NMR integration standard. Comparison of the ${ }^{1} \mathrm{H}$ NMR integration values for a diagnostic 1-hexyl-phenylsilane peak in the product (4.46 ppm, $2 \mathrm{H}, \mathrm{t},{ }^{3} J_{\mathrm{HH}}=3.7 \mathrm{~Hz}, \mathrm{CH}_{2} \mathrm{Si} H_{2} \mathrm{Ph}$ ) [33] with the peaks for the integration standard [14] allowed for calculation of a hydrosilylation yield of $97 \%$ (trial 1) and 100\% (trial 2). Data reported in Figure 10 represent an average of at least two independent trials. In each case, $2.5 \mathrm{~mol} \% \mathrm{Fe}$ was used, given mol $\%=(\mathrm{mol} \mathrm{Fe} /$ total mol substrates $) * 100 \%$ [4].

\subsection{Single crystal X-ray diffraction}

Single crystals suitable for X-ray diffraction were coated with degassed Paratone-N oil (Fisher Scientific) in an inert atmosphere glovebox and shipped under nitrogen to Eastern Illinois University (EIU). At the EIU integrative applied crystallography center, the crystals were quickly transferred to the Bruker APEXII CCD diffractometer and data were collected using phi and omega scans with graphite monochromatic $\mathrm{Cu} K \alpha(\lambda=1.54178 \AA)$ radiation. Data sets were corrected for Lorentz and polarization effects. The criterion for observed reflections is $I>2 \sigma(I)$. Lattice parameters were determined from least-squares analysis and reflection data. Empirical absorption corrections were applied using TWINABS (4a) and SADABS (4b) [34]. Structures were solved by direct methods and refined by full-matrix least-squares analysis on $F^{2}$ using $\mathrm{X}$ SEED [35] equipped with SHELX-2014/7 [36]. All non-hydrogen atoms for $4 \mathbf{a}$ and $\mathbf{4 b}$ were refined anisotropically unless specified by full-matrix least-squares on $F^{2}$ by the use of the SHELX-2014/7-XL [36] program. The diffuse electron density in the crystal lattice of $\mathbf{4 b}$ 
corresponding to 520 electrons and $1.5 \mathrm{CH}_{2} \mathrm{Cl}_{2}$ molecules was removed with the SQUEEZE [37] function in PLATON [38].

\subsection{Mössbauer spectroscopy}

${ }^{57} \mathrm{Fe}$ Mössbauer spectroscopic studies were performed using a See Co. Mössbauer Spectroscopy System MS4 with a VT4 velocity transducer, a 100 mCi Co-57 Mössbauer source, and a CryoIndustries closed-cycle cryostat. Isomer shifts were determined relative to iron foil ( $\alpha$ Fe) at $298 \mathrm{~K}$. The fitting of Lorentzian lines was performed with custom proprietary software.

\subsection{Quantum-chemical computations.}

All DFT calculations were performed in the gas phase with the ORCA program package [39]. The geometry optimizations of the complexes and single-point energy calculations on the optimized geometries were carried out at the B3LYP level of DFT [40-42]. This hybrid functional often produces better results for transition metals than pure gradient-corrected functionals, especially with respect to metal-ligand covalency [43]. The all-electron Gaussian basis sets were those developed by the Ahlrichs group [44-46]. Triple- $\zeta$ quality basis sets def2TZVP with one set of polarization functions on the metals and on the atoms directly coordinated to the metal center were used. For the carbon and hydrogen atoms, slightly smaller polarized split-valence def2-SV(P) basis sets were used that were of double- $\zeta$ quality in the valence region and contained a polarizing set of d-functions on the non-hydrogen atoms. Auxiliary basis sets were chosen to match the orbital basis set [47-49]. The RIJCOSX [50-52] approximation was used to accelerate the calculations. Numerical frequencies were calculated at the same level of 
theory to confirm that a global energy minimum had been achieved and that there were no imaginary frequencies for both ${ }^{\mathrm{dpp}} \mathrm{BIANFeBr}_{2}$ (4a) and ${ }^{\mathrm{Mes}} \mathrm{BIANFeBr}_{2}$ (4b).

Computational results were described using the broken-symmetry (BS) approach by Ginsberg [53] and Mouesca [54]. Since several broken-symmetry solutions to the spinunrestricted Kohn-Sham equations may be obtained, the general notation of BS $(m, n)[55]$ has been adopted where $m$ denotes the number of spin up electrons and $n$ denotes the number of spin down electrons at the two interacting fragments. Canonical and corresponding [56] orbitals, as well as spin density plots, were generated using the program Chimera [57].

Non-relativistic single-point calculations on the optimized geometry were carried out to predict Mössbauer spectral parameters (i.e. isomer shifts and quadrupole splittings). These calculations employed the $\mathrm{CP}(\mathrm{PPP})$ basis set for iron [58]. The Mössbauer isomer shifts were calculated from the computed electron densities at the iron centers [27,59].

\section{Appendix A. Supplementary data}

CCDC 1427382 and 1427793 contain supplementary crystallographic data for $\mathbf{4 a}$ and $\mathbf{4 b}$, respectively. These data can be obtained free of charge via http://www.ccdc.cam.ac.uk/conts/retrieving.html, or from the Cambridge Crystallographic Data Centre, 12 Union Road, Cambridge CB2 1EZ, UK; fax: (+44) 1223-336-033; or e-mail: deposit@ccdc.cam.ac.uk. Also provided: Mössbauer spectra of 4a and 4b recorded at higher temperatures, a ${ }^{1} \mathrm{H}$ NMR spectrum of $\mathbf{4 b} \mathbf{\mathbf { T H F }}$, the qualitative molecular orbital diagrams for $\mathbf{4 a}$ and ${ }^{d p p}$ BIANFe(tol) (RKS solution), and representative input files and a .xyz file for the computations. 


\section{Acknowledgements}

We acknowledge the donors of the American Chemical Society Petroleum Research Fund \#54044-UNI3 (H.M.H.), National Science Foundation NSF-MRI award CHE-1427411 for the $400 \mathrm{MHz}$ NMR spectrometer (H.M.H.), and NSF-MRI award CHE-0722547 for the X-ray diffractometer (K.A.W.). We also acknowledge funding from Knox College, The Scripps Foundation for the Mössbauer spectrometer (C.E.S.) and the IR spectrometer (H.M.H.), the Paul K. Richter \& Evalyn E. Cook Memorial Trust (M.J.S., A.V., and L.D.), and the Ford Fellowship program (M.J.S.) for support of this research. We thank Carsten Milsmann for productive discussions of the computations and Marika Takemura for her initial preparation of $\mathbf{4 a}$.

\section{References}

[1] B. Marciniec, Hydrosilylation: A Comprehensive Review on Recent Advances, Springer, Berlin (2009).

[2] D. Troegel, J. Stohrer, Coord. Chem. Rev. 255 (2011) 1440.

[3] M.D. Greenhalgh, A.S. Jones, S.P. Thomas, ChemCatChem 7 (2015) 190.

[4] A.M. Tondreau, C.C.H. Atienza, K.J. Weller, S.A. Nye, K.M. Lewis, J.G.P. Delis, P.J. Chirik, Science 335 (2012) 567.

[5] A.M. Tondreau, C.C.H. Atienza, J.M. Darmon, C. Milsmann, H.M. Hoyt, K.J. Weller, S.A. Nye, K.M. Lewis, J. Boyer, J.G.P. Delis, E. Lobkovsky, P.J. Chirik, Organometallics 31 (2012) 4886.

[6] K. Kamata, A. Suzuki, Y. Nakai, H. Nakazawa, Organometallics 31 (2012) 3825.

[7] J.Y. Wu, B.N. Stanzl, T. Ritter, J. Am. Chem. Soc. 132 (2010) 13214. 
[8] D. Peng, Y. Zhang, X. Du, L. Zhang, X. Leng, M.D. Walter, Z. Huang, J. Am. Chem. Soc. 135 (2013) 19154.

[9] S.C. Bart, E.J. Hawrelak, A.K. Schmisseur, E. Lobkovsky, P.J. Chirik, Organometallics 23 (2004) 237

[10] S.C. Bart, E.J. Hawrelak, E. Lobkovsky, P.J. Chirik, Organometallics 24 (2005) 5518.

[11] A. Paulovicova, U. El-Ayaan, K. Shibayama, T. Morita, Y. Fukuda, Eur. J. Inorg. Chem. (2001) 2641.

[12] F.S. Wekesa, R. Arias-Ugarte, L. Kong, Z. Sumner, G.P. McGovern, M. Findlater, Organometallics 34 (2015) 5051.

[13] P.J. Chirik, Inorg. Chem. 50 (2011) 9737.

[14] M.D. Greenhalgh, D.J. Frank, S.P. Thomas, Adv. Synth. Catal. 356 (2014) 584.

[15] J. Yuan, Z. Zhang, W. Xu, J. Zhao, Y. Mu, J. Chen, Transition Met Chem 39 (2014) 769.

[16] L.E.N. Allan, M. P. Shaver, A.J.P. White, V.C. Gibson, Inorg. Chem. 46 (2007) 8963.

[17] J. Yuan, X. Wang, T. Mei, Y. Liu, C. Miao, X. Xie, Transition Met Chem 36 (2011) 433.

[18] L. Yang, D.R. Powell, R.P. Houser, Dalton Trans. (2007) 955.

[19] K.P. Butin, E.K. Beloglazkina, N.V. Zyk, Russian Chemical Reviews 74 (2005) 531.

[20] I.L. Fedushkin, A.A. Skatova, N.M. Khvoinova, A.N. Lukoyanov, G.K. Fukin, S.Y. Ketkov, M.O. Maslov, A.S. Bogomyakov, V.M. Makarov, Russ.Chem.Bull., Int.Ed. 62 (2013) 2122.

[21] U. El-Ayaan, A.A.-M. Abdel-Aziz, Eur. Jour. Med. Chem. 40 (2005) 1214.

[22] U. El-Ayaan, F. Murata, S. El-Derby, Y. Fukuda, J. Mol. Struct. 692 (2004) 209.

[23] P. Gütlich, E. Bill, A.X. Trautwein, Mossbauer Spectroscopy and Transition Metal Chemistry: Fundamentals and Applications; Springer: Heidelberg, 2011; pp 83-89. 
[24] G.R. Fulmer, A.J.M. Miller, N.H. Sherden, H.E. Gottlieb, A. Nudelman, B.M. Stoltz, J. E. Bercaw, K.I. Goldberg, Organometallics 29 (2010) 2176.

[25] N. Muresan, C.C. Lu, M. Ghosh, J.C. Peters, M. Abe, L.M. Henling, T. Weyhermöller, E. Bill, K. Weighardt, Inorg. Chem. 47 (2008) 4579.

[26] F. Neese, J Biol Inorg Chem 11 (2006) 702.

[27] R. Römelt, S. Ye, F. Neese, Inorg. Chem. 48 (2009) 784.

[28] V. Bachler, G. Olbrich, F. Neese, K. Wieghardt, Inorg. Chem. 41 (2002) 4179.

[29] J. M. Hoyt, K. T. Sylvester, S. P. Semproni, P. J. Chirik, J. Am. Chem. Soc. 135 (2013) 4862.

[30] A.B. Pangborn, M.A. Giardello, R.H. Grubbs, R.K. Rosen, F.J. Timmers, Organometallics $15(1996) 1518$.

[31] S.K. Sur, J. Magn. Res. 82 (1989) 169.

[32] D. J. Tempel, L. K. Johnson, R. L. Huff, P. S. White, M. Brookhart, J. Am. Chem. Soc. 122 (2000) 6686 and references therein.

[33] M. Konkol, M. Kondracka, P. Voth, T. P. Spaniol, J. Okuda, Organometallics 27 (2008) 3774.

[34] G. M. Sheldrick, SADABS — Program for Area Detector Absorption Corrections, University of Göttingen, Göttingen, Germany, 2013.

[35] L. J. Barbour, J. Supramol. Chem. 1 (2001) 189.

[36] G. M. Sheldrick, Acta Crystallogr., Sect. A: Fundam. Crystallogr. 64 (2008) 112.

[37] A.L. Speck, Acta Cryst. D65 (2009) 148.

[38] A.L. Speck, J. Appl. Crystallogr. 36 (2003) 7. 
[39] F. Neese, ORCA: An ab initio, DFT and Semiempirical Electronic Structure Package, version 3.0.3; Institut für Physikalische und Theoretische Chemie, Universität Bonn: Bonn, Germany (2013).

[40] C.T. Lee, W.T. Yang, R.G. Parr, Phys. Rev. B 37 (1988) 785.

[41] A.D. Becke, J. Chem. Phys. 84 (1986) 4524.

[42] A.D. Becke, J. Chem. Phys. 98 (1993) 5648.

[43] F. Neese, E.I. Solomon, In Magnetism: From Molecules to Materials; J.S. Miller, M. Drillon, Eds.; Wiley: New York, 2002; Vol. 4, p 345.

[44] A. Schäfer, H. Horn, R. Ahlrichs, J. Chem. Phys. 97 (1992) 2571.

[45] A. Schäfer, H. Horn, R. Ahlrichs, J. Chem. Phys. 100 (1994) 5829.

[46] F. Weigend, R. Ahlrichs, Phys. Chem. Chem. Phys. 7 (2005) 3297.

[47] K. Eichkorn, F. Weigend, O. Treutler, R. Ahlrichs, Theor. Chem. Acc. 97 (1997) 119.

[48] K. Eichkorn, O. Treutler, H. Öhm, M. Häser, R. Ahlrichs, Chem. Phys. Lett. 240 (1995) 283.

[49] K. Eichkorn, O. Treutler, H. Öhm, M. Häser, R. Ahlrichs, R. Chem. Phys. Lett. 242 (1995) 652.

[50] F. Neese, F. Wennmohs, A. Hansen, U. Becker Chem. Phys. 356 (2009) 98.

[51] S. Kossmann, F. Neese, Chem. Phys. Lett. 481 (2009) 240.

[52] F. Neese, J Comput. Chem. 24 (2003) 1740.

[53] A. P. Ginsberg, J. Am. Chem. Soc. 102 (1980) 111.

[54] L. Noodleman, C.Y. Peng, D.A. Case, J.M. Mouesca, Coord. Chem. Rev. 144 (1995) 199.

[55] B. Kirchner, F. Wennmohs, S. Ye, F. Neese, Curr. Opin. Chem. Biol. 11 (2007) 134.

[56] F. Neese, J. Phys. Chem. Solids 65 (2004) 781. 
[57] E. F. Pettersen, T.D. Goddard, C. C Huang, G. S. Couch, D. M. Greenblatt, E. C. Meng, T. E. Ferrin, J. Comput. Chem. 25 (2004) 1605.

[58] F. Neese, Inorg. Chim. Acta 337 (2002) 181.

[59] S. Sinnecker, L.D. Slep, E. Bill, F. Neese, Inorg. Chem. 44 (2005) 2245. 